\title{
Quantification of the volatility of secondary organic compounds in ultrafine particles during nucleation events
}

\author{
J. R. Pierce ${ }^{1}$, I. Riipinen ${ }^{2,3,4}$, M. Kulmala ${ }^{2}$, M. Ehn ${ }^{2,}{ }^{*}$, T. Petäjä ${ }^{2}$, H. Junninen ${ }^{2}$, D. R. Worsnop ${ }^{2,5}$, and N. M. Donahue ${ }^{3}$ \\ ${ }^{1}$ Department of Physics and Atmospheric Science, Dalhousie University, Halifax, Nova Scotia, Canada \\ ${ }^{2}$ Division of Atmospheric Sciences, Department of Physics, University of Helsinki, Helsinki, Finland \\ ${ }^{3}$ Center for Atmospheric Particle Studies, Carnegie Mellon University, Pittsburgh, Pennsylvania, USA \\ ${ }^{4}$ Institute of Chemical Engineering and High-Temperature (ICE-HT) Processes, Patras, Greece \\ ${ }^{5}$ Aerodyne Research Inc., MA-01821, Billerica, MA, USA \\ * currently at: Institute for Energy and Climate Research, Forschungszentrum Jülich, Jülich, Germany
}

Received: 20 April 2011 - Published in Atmos. Chem. Phys. Discuss.: 11 May 2011

Revised: 11 August 2011 - Accepted: 26 August 2011 - Published: 5 September 2011

\begin{abstract}
Condensation of secondary organic compounds onto ultrafine aerosols is important for growing these particles to sizes where they can act as cloud condensation nuclei. The organic flux to ultrafine particles depends strongly on the volatility of the condensing compounds. This paper presents quantitative estimates of the volatility of secondary organic aerosol (SOA) in freshly nucleated particles. We examine 13 nucleation/growth events in two remote continental locations, Hyytiälä, Finland and Egbert, ON, Canada. Two independent methods are used to quantify the volatility of the growing nucleation mode: (1) modelling of the growing nucleation mode to determine which volatilities allow the model to reproduce observed growth, and (2) modelling of the evaporation of heated aerosols in a Volatility Differential Mobility Particle Sizer to determine which volatilities allow the model to reproduce the observed evaporation. We find that the average saturation vapor concentration $\left(C^{*}\right)$ in the freshly nucleated particles (once $D_{\mathrm{p}}>$ $3 \mathrm{~nm}$ ) is likely less than $10^{-3}-10^{-2} \mathrm{\mu g} \mathrm{m}^{-3}$ (this corresponds to $3 \times 10^{6}-3 \times 10^{7}$ molecules $\mathrm{cm}^{-3}$ and a saturation vapor pressure of $10^{-8}-10^{-7} \mathrm{~Pa}$ ). This maximum volatility depends somewhat on other uncertain factors that affect the size-dependent condensation of secondary organic compounds such as the surface tension, mass accommodation coefficient and the volatility of the pre-existing aerosols. However, our tests suggest that under no reasonable assumptions can the SOA in the ultrafine particles contain a majority of compounds with $C^{*}>10^{-2} \mu \mathrm{g} \mathrm{m}{ }^{-3}$. We demonstrate that
\end{abstract}

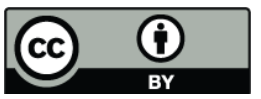

Correspondence to: J. R. Pierce (jeffrey.pierce@dal.ca) the growth could be driven by either gas-phase or particlephase chemistry but cannot conclude which is responsible for the low-volatility SOA.

\section{Introduction}

Atmospheric aerosols have important effects on climate and human health. The strength of these effects depends greatly on the size and composition of the aerosols. Aerosols affect climate directly by scattering and absorbing solar radiation and indirectly by acting as a nuclei for cloud droplets. These cloud condensation nuclei $(\mathrm{CCN})$ in turn affect cloud optical properties and lifetime (Twomey, 1974, 1977, 1991; Albrecht, 1989). Hygroscopic particles generally must be at least $30-100 \mathrm{~nm}$ in dry diameter to act as a $\mathrm{CCN}$, and more hydrophobic particles require larger minimum diameters than hygroscopic ones (Dusek et al., 2006). Furthermore, the number concentration of $\mathrm{CCN}$ is one of the strongest drivers of aerosol effects on clouds, and the $\mathrm{CCN}$ concentration for a given aerosol mass depends greatly on the aerosol size distribution (Pierce and Adams, 2007). The deposition patterns of particles in the human lung - and thus the health impacts of aerosols - also depend on particle size (Peters et al., 1997). Although the details regarding the effects of aerosol composition on health are still uncertain, it is likely that composition is important (Godleski et al., 2000). Therefore, to predict accurately the effects of aerosols on climate and health, it is necessary to have a thorough understanding of the processes that shape particle size and composition distributions in the atmosphere.

Published by Copernicus Publications on behalf of the European Geosciences Union. 
Nucleation is the dominant source of aerosol number in the atmosphere (Kulmala et al., 2004; Kulmala and Kerminen, 2008), and - through condensational growth - can be an important source of CCN in many parts of the atmosphere (Lihavainen et al., 2003; Kerminen et al., 2005; Laaksonen et al., 2005; Merikanto et al., 2009; Makkonen et al., 2009; Pierce and Adams, 2009a; Spracklen et al., 2010; Wang and Penner, 2009; Yu and Luo, 2009). The condensation rate of atmospheric vapors onto the nucleated particles is a key factor governing whether freshly nucleated particles (with diameters around $1 \mathrm{~nm}$ ) and other ultrafine particles will grow to sizes where they can affect climate. Because freshly nucleated particles in tropospheric conditions are usually scavenged by coagulation with larger particles on timescales much less than one day, fast condensational growth rates are needed in order for nucleated particles to survive to larger sizes (Pierce and Adams, 2007).

Secondary organic compounds are one of the dominant species condensing onto aerosols in the atmosphere (Jimenez et al., 2009). While our understanding of secondary organic aerosol (SOA) has increased greatly in the past decade, the properties of organic aerosol, such as volatility and hygroscopicity, are still far more uncertain than those of other aerosol constituents such as ammonium sulfate. Organic aerosol is made up of thousands of compounds, and the composition evolves with time due to chemical reactions (Kanakidou et al., 2005). SOA is formed when relatively volatile organic compounds are oxidized to form products with a low enough volatility to reside principally in the condensed phase. Precursors include volatile organic compounds (VOCs) as well as intermediate volatility organic compounds (IVOCs) (Donahue et al., 2009). The traditional view of SOA formation is that the chemical reactions to form SOA take place primarily in the gas phase; however, aerosol- or cloud-phase chemistry is also a potentially important source of SOA mass (Hallquist et al., 2009; Wang et al., 2010; Lim et al., 2010). Regardless of the phase of the reaction, this addition of SOA mass to pre-existing aerosol causes a net condensational flux to the aerosol phase. Under the right conditions, this condensation can lead to rapid growth of ultrafine particles to larger sizes (Riipinen et al., 2011).

Determining the equilibrium partitioning of organic species between the gas phase and bulk aerosol phase (integrated over all aerosol sizes) is a relatively straightforward procedure if the volatilities of the organics are known. Aerosol absorptive partitioning theory (Pankow, 1994) has led to frameworks, such as 2-product models (Odum et al., 1996) and the Volatility-Basis Set (Donahue et al., 2006). In these frameworks, organic species with similar volatilities are lumped together to form anywhere between 2 and 10 pseudo-species with different effective saturation concentrations $\left(C^{*}\right)$ typically given in units of $\mu \mathrm{g} \mathrm{m}^{-3}$ (a $C^{*}$ of $1 \mu \mathrm{g} \mathrm{m}^{-3}$ corresponds to about $3 \times 10^{9}$ molecules $\mathrm{cm}^{-3}$ and a saturation vapor pressure of about $10^{-5} \mathrm{~Pa}$ for species with molecular weights around $200 \mathrm{~g} \mathrm{~mol}^{-1}$ ). These frameworks have been shown to be efficient for simulations of aerosol mass concentrations in 3-D chemical transport models, and the volatilities of the compounds forming most of the SOA mass are relatively well characterized (Kanakidou et al., 2005; Lane et al., 2008; Murphy et al., 2009). However, these aerosol-mass-only equilibrium models did not include the simulation of the growth of ultrafine particles to climate-relevant sizes.

On the other hand, size-dependent condensation of secondary organic compounds is less well understood than the simple partitioning of material between the condensed and gas phases, especially their contribution to ultrafine growth. Partitioning is an equilibrium description, while condensational growth is by definition dynamic. Three factors complicate the condensational behavior of the fraction of SOA that contributes to the growth of ultrafine aerosol:

1. The exact identities and saturation vapor pressures of the organic molecules condensing on (or forming in) the ultrafine aerosol are largely unknown.

2. Surface tension increases the effective saturation concentration of each SOA species in small particles. This inhibits net condensation (or enhances net evaporation) of the species to/from small particles. However, the exact values of the surface tension of atmospheric aerosol particles are not known.

3. The mixing ratios of SOA components in the aerosol phase are generally not constant across different aerosol sizes - partly because of the surface tension effect, and partly due to different-sized aerosols having different sources and histories. These composition differences also create differences in the effective saturation concentration of SOA between different sizes of aerosols.

4. Organic aerosols may form complex multi-phase mixtures. SOA is typically modeled as a pseudo-ideal single-phase liquid mixture, but recent results show this may not always be correct (Virtanen et al., 2010; Cappa and Wilson, 2011).

These issues of size-dependent SOA condensation described above can be seen in the equation for the net condensational mass flux $J$, of SOA volatility species $i$, to particles of diameter $D_{\mathrm{p}}$ :

$J_{i}=\frac{\pi}{4} D_{\mathrm{p}}^{2} \alpha_{\mathrm{m}, i} \overline{c_{i}} \beta_{i}\left(D_{\mathrm{p}}, \alpha_{\mathrm{m}, i}\right)\left[C_{i, \infty}-C_{i}^{*} x_{i}\left(D_{\mathrm{p}}\right) \exp \left(\frac{4 \sigma V_{\mathrm{m}, i}}{D_{\mathrm{p}} R T}\right)\right](1)$

where $\alpha_{\mathrm{m}, i}$ is the mass accommodation coefficient of species $i, \bar{c}_{i}$ is the mean velocity of species $i, \beta_{i}$ is the correction factor for particles larger than the kinetic regime, $C_{i, \infty}$ is the gas-phase concentration of SOA species $i, C_{i}^{*}$ is the saturation concentration of pure SOA species $i$ over a flat surface (which includes the effective activity coefficient of the species), $x_{i}$ is the mole fraction of SOA species $i$ (or mass 
fraction of using the Volatility Basis Set) in the organicaerosol partitioning phase, $\sigma$ is the surface tension of the aerosol, $V_{\mathrm{m}, i}$ is the molar volume of $i$ in the condensed phase, $R$ is the gas constant and $T$ is the temperature. We define the effective saturation concentration of SOA species $i, C_{i, \text { eff }}^{*}$ :

$C_{i, \text { eff }}^{*}=C_{i}^{*} x_{i}\left(D_{\mathrm{p}}\right) \exp \left(\frac{4 \sigma V_{\mathrm{m}, i}}{D_{\mathrm{p}} R T}\right)$

In Eqs. (1) and (2), the mole fraction effects $\left(x_{i}\left(D_{\mathrm{p}}\right)\right)$ and the surface tension effects $\left(\exp \left(4 \sigma V_{\mathrm{m}, i} /\left(D_{\mathrm{p}} R T\right)\right)\right)$ both modify the effective saturation concentration and the condensational driving force (the difference between the gas phase concentration and the effective saturation concentration, $C_{i, \infty}-C_{i, \text { eff }}^{*}$ ). In absence of these two effects (or cases where $C_{i, \infty} \gg C_{i, \text { eff }}^{*}$, the size-dependent condensation will be proportional to the Fuchs-corrected surface area $\left(\pi / 4 D_{\mathrm{p}}^{2} \alpha_{\mathrm{m}, i} \beta_{i}\left(D_{\mathrm{p}}, \alpha_{\mathrm{m}, i}\right)\right)$, similar to sulfuric acid condensation. There may, however, be significant deviations from this behavior for SOA. These deviations will be minor for lowvolatility SOA because $C_{i, \infty} \gg C_{i \text {,eff }}^{*}$ during condensation, but may be very important for semi-volatile species where $C_{i, \infty} \approx C_{i, \text { eff }}^{*}$ even during condensation.

In addition to these effects related to the simple condensation of the pure species, particle-phase chemistry may also modify the volatility of the organic compounds in the aerosol phase. Generally, the products of the chemistry may be more or less volatile. However, acid-base reactions (e.g. salt formation) and polymerization (e.g. oligomerization) reactions (Hallquist et al., 2009; Wang et al., 2010; Lim et al., 2010; Smith et al., 2010), which are the two main mechanisms that have been suggested to affect SOA, would create lower volatility species. These reactions decrease the aerosol-phase mole fractions of the higher-volatility reactants, driving more reactants into the aerosol phase. Thus, particle-phase chemistry that forms lower-volatility species will create a net condensational flux to the aerosol phase. Additionally, particle-phase chemistry is composition dependent and thus also size dependent. Therefore, it is important to know both the volatility of the products of particle-phase chemistry as well as particle sizes in which the chemistry is occurring.

SOA volatility studies in smog chambers have found SOA to be dominated by semi-volatile compounds and have either not found or not focused on low-volatility SOA (e.g. Pathak et al., 2007). This has led aerosol modelers to adopt SOA schemes where SOA is entirely semi-volatile $\left(C^{*}>\right.$ $10^{-1} \mu \mathrm{g} \mathrm{m}^{-3}$ ). For bulk aerosol models that do not explicitly simulate the aerosol size distribution, this method has been shown to work well for predicting SOA mass (Lane et al., 2008; Murphy et al., 2009). Contrary to the lab measurements of SOA, field measurements have shown the presence of both semi-volatile and lower-volatility organics, and these correlate with less oxidized and more oxidized organic aerosol, respectively (Jimenez et al., 2009).
These field measurements have shown two distinct aerosol factors measured by the Aerosol Mass Spectrometer (AMS) coupled with a thermodenuder: semi-volatile oxidized organic aerosol (SV-OOA) and low-volatility oxidized organic aerosol (LV-OOA). Furthermore, even the SV-OOA in these field measurements was found to have a significantly lower volatility than SOA measured in smog chamber experiments (Cappa and Jimenez, 2010). Because the size-dependent SOA condensation depends on volatility, the semi-volatileonly modeling approach likely fails when predicting the aerosol size distribution.

As far as we know, the only attempts to account for both low-volatility and semi-volatile SOA net-condensational behavior in global aerosol microphysics models are recent papers by Yu (2011) and Riipinen et al. (2011). Yu (2011) treated freshly formed SOA as semi-volatile material that partitioned to the size distribution proportionally to aerosol mass. Vapors from that semi-volatile SOA were then presumed to oxidize in the gas phase to form low-volatility SOA on a timescale proportional to $\mathrm{OH}$ concentration. Those lowvolatility SOA products then condensed onto aerosol surface area. These processes were designed to mimic the aging process of SV-OOA to LV-OOA discussed in Jimenez et al. (2009). Updating the model from mass-based condensation to also including condensation onto aerosol surface area increased surface CCN concentrations by 5-50\% depending on location. Our previous paper, Riipinen et al. (2011), looked at 7 nucleation and growth events in Hyytiälä, Finland and Egbert, ON, Canada and found that at least half of the SOA mass formed during the nucleation/growth events needed to be condensed onto the aerosol surface area rather than being partitioned to the size distribution proportionally to the aerosol mass. The organics condensing onto the surface area were found to evolve similarly to measurements of LV-OOA and the organics condensing into the mass distribution were found to evolve similarly to measurements of SV-OOA. We applied these results to a global aerosol microphysics model and, similarly to Yu (2011), predicted that $\mathrm{CCN}$ concentrations are more than $25 \%$ higher in many parts of the world when low-volatility, surface-area based condensation is allowed to occur. The main conclusion from both Yu (2011) and Riipinen et al. (2011) is that in order for aerosol microphysics models to simulate both aerosol number and mass properly, the details of size-dependent SOA condensation - and thus volatility - must be known. However, we are still just beginning to understand how SOA volatility evolves in the atmosphere and the roles of gas and particle-phase chemistry in this evolution.

This paper is a continuation of our work in Riipinen et al. (2011) and builds off of earlier work of Kulmala et al. (1998). In Riipinen et al. (2011) we did not attempt to quantify the volatility (saturation vapor concentrations) or other properties of the condensing SOA beyond determining that half or more needed to condense based on surface area. Kulmala et al. (1998) used an aerosol dynamics 
model to determine an upper bound for the volatility for a single condensing species on nucleating particles; however, because measurements of time-resolved sulfuic acid and organic aerosol mass were not standard practice at the time of the study, the results were limited. The goals of this current paper are to:

1. Quantify upper bounds on the volatility of the secondary organic compounds added to the growing ultrafine mode based on data from boreal environments.

2. Explore the sensitivity of ultrafine growth to SOA volatility, surface tension and accommodation coefficients.

3. Determine the effects that size-dependent particle-phase chemistry could have on the growth of ultrafine particles.

To constrain our model we employ two independent methods focusing on data from 14 nucleation/growth events. In the first method we estimate how growth depends on volatility in a box model including size-resolved aerosol microphysics and a fully kinetic treatment of SOA condensation/evaporation. In the second method we determine the mean aerosol volatility necessary to explain the size of residual aerosols after heating in a Volatility Differential Mobility Particle Sizer (VDMPS).

\section{Methods}

\subsection{Locations and days with nucleation events}

We analyze nucleation/growth events in two locations, Hyytiälä, Finland (Kulmala et al., 2001; Hari and Kulmala, 2005) (14 March 2007-5 May 2007) and Egbert, ON, Canada (Chang et al., 2010) (21 May 2007-22 May 2007) (Riipinen et al., 2011). Table 1 summarizes the days analyzed in these locations. To gain insight into the formation and growth rates of the freshly-formed aerosol and the general evolution of the aerosol size distributions we used Differential Mobility Particle Sizer (DMPS) or Scanning Mobility Particle Sizer (SMPS) data in Hyytiälä and Egbert, respectively. To quantify (1) the chemical composition of the pre-existing aerosol and (2) the total condensational flux of SOA to the aerosol phase, we used particle composition data collected with the Aerosol Mass Spectrometer (AMS) at both sites. In Hyytiälä, we also use measurements of atmospheric sulfuric acid vapor concentrations collected with the Chemical Ionization Mass Spectrometer (CIMS) (Eislele and Tanner, 1993; Petäjä et al., 2009) for the period of 9 April 2007-5 May 2007 as well as data on the volatility of the aerosol collected with the Volatility Differential Mobility Particle Sizer (VDMPS) setup (Ehn et al., 2007) for the period of 14 March 2007-17 April 2007. The data sets and experimental methods for Hyytiälä and Egbert are described in detail in Riipinen et al. (2011).

We analyzed the data with two different approaches in order to yield an estimate on the maximum volatility of the compounds growing the nucleation mode: (1) we simulated the aerosol growth with an aerosol microphysics box model and tested different combinations of $C^{*}$ values of the condensing species in order to find the best possible correspondence between the measured and the modeled data, and (2) we used a dynamic evaporation model to simulate the evaporation of the nucleation mode aerosol in the VDMPS system and this way yielded a second independent estimate for the volatility of the nucleation mode species. The details of these two approaches are described in the following subsections. Unfortunately no VDMPS data was available for the Canadian sites, so the latter approach could only be applied for Hyytiälä data. Also, the VDMPS data were unusable on 9 April and 16 April at Hyytiälä. No AMS and CIMS data were available for the earlier Hyytiälä dates, so only the VMPS analysis is done for dates prior to April 2007.

For all of these events (at least where CIMS and AMS data are available) condensation of $\mathrm{H}_{2} \mathrm{SO}_{4}$ cannot on its own explain the observed growth of the nucleated particles (Riipinen et al., 2011). Table 1 shows that the maximum possible growth rates of the nucleation-mode particles from sulfuric acid alone derived from the CIMS measurements are much smaller than the observed growth rates (generally by an order of magnitude). Furthermore, the total change in mass measured by the AMS between the start of the nucleation event and the point where growth stops is larger for organics than sulfate in all cases, consistent with observations at Hyytiälä by Allan et al. (2006). In many cases, the sulfate mass does not change at all during the growth period.

\subsection{Aerosol microphysical box model with kinetic SOA condensation/evaporation}

To understand the effect of SOA volatility on growth during 9 nucleation/growth events in Hyytiälä and Egbert, we use a box-model version of the TwO Moment Aerosol Sectional (TOMAS) microphysics model (Adams and Seinfeld, 2002; Pierce and Adams, 2009b; Riipinen et al., 2011). This version of the TOMAS box model uses 36 lognormally spaced size sections to represent dry diameters of $3 \mathrm{~nm}$ to $10 \mu \mathrm{m}$. The modeled aerosol species (within each size section) are sulfate, water and 8 organic aerosol species representing lumped species with lognormally spaced $C^{*}$ s between $10^{-5}$ and $10^{2} \mu \mathrm{g} \mathrm{m}^{-3}$ (Volatility Basis Set, Donahue et al., 2006). The modeled gas-phase species are sulfuric acid and the 8 gas-phase organic volatility species. The numerics of condensation and coagulation are discussed in Adams and Seinfeld (2002). Sulfuric acid and organics undergo condensation/evaporation using Eq. (1). The saturation concentration of sulfuric acid is assumed to be negligible due to the presence of aerosol water (Seinfeld and Pandis, 2006). The 
Table 1. Summary of analyzed events.

\begin{tabular}{|c|c|c|c|c|c|c|c|c|c|}
\hline Location & $\begin{array}{l}\text { Date } \\
(2007)\end{array}$ & $\begin{array}{l}\text { Max diameter } \\
\text { of nucleation } \\
\text { mode }(\mathrm{nm})^{\mathrm{a}}\end{array}$ & $\begin{array}{l}\text { Mean growth } \\
\text { rate }\left(\mathrm{nm} \mathrm{h}^{-1}\right)^{\mathrm{a}}\end{array}$ & $\begin{array}{l}\operatorname{Max}\left[\mathrm{H}_{2} \mathrm{SO}_{4}\right] \\
\left(\operatorname{molec~} \mathrm{cm}^{-3}\right)^{b}\end{array}$ & $\begin{array}{l}\text { Max growth rate } \\
\text { from } \mathrm{H}_{2} \mathrm{SO}_{4} \\
\left(\mathrm{~nm} \mathrm{~h}^{-1}\right)^{\mathrm{b}}\end{array}$ & $\begin{array}{l}\text { Change in total } \\
\text { sulfate }\left(\mu \mathrm{g} \mathrm{m}^{-3}\right)^{\mathrm{c}}\end{array}$ & $\begin{array}{l}\text { Change in total } \\
\text { organics }\left(\mu \mathrm{g} \mathrm{m}^{-3}\right)^{\mathrm{c}}\end{array}$ & $\begin{array}{l}\text { Growth } \\
\text { analysis }\end{array}$ & $\begin{array}{l}\text { VDMPS } \\
\text { analysis }\end{array}$ \\
\hline Hyytiälä, Finland & $14 \mathrm{Mar}$ & 38 & 3.5 & No data & No data & No data & No data & No & Yes \\
\hline Hyytiälä, Finland & $15 \mathrm{Mar}$ & 45 & 4.5 & No data & No data & No data & No data & No & Yes \\
\hline Hyytiälä, Finland & $16 \mathrm{Mar}$ & 33 & 2.8 & No data & No data & No data & No data & No & Yes \\
\hline Hyytiälä, Finland & 31 Mar & 36 & 3.0 & No data & No data & No data & No data & No & Yes \\
\hline Hyytiälä, Finland & $9 \mathrm{Apr}$ & 14 & 1.2 & $3.0 \times 10^{6}$ & 0.12 & 0.25 & 0.4 & Yes & No \\
\hline Hyytiälä, Finland & $10 \mathrm{Apr}$ & 21 & 2.1 & $7.8 \times 10^{6}$ & 0.33 & 0.5 & 0.9 & Yes & Yes \\
\hline Hyytiälä, Finland & $14 \mathrm{Apr}$ & 25 & 2.5 & $2.9 \times 10^{6}$ & 0.12 & 0 & 0.3 & Yes & Yes \\
\hline Hyytiälä, Finland & $15 \mathrm{Apr}$ & 36 & 3 & $1.7 \times 10^{6}$ & 0.07 & 1 & 1.4 & Yes & Yes \\
\hline Hyytiälä, Finland & $16 \mathrm{Apr}$ & 17 & 1.7 & $3.2 \times 10^{6}$ & 0.13 & 0.7 & 0.8 & Yes & No \\
\hline Hyytiälä, Finland & $17 \mathrm{Apr}$ & 30 & 3.3 & $0.7 \times 10^{6}$ & 0.03 & 0 & 0.6 & Yes & Yes \\
\hline Hyytiälä, Finland & 5 May & 21 & 2.7 & $1.8 \times 10^{6}$ & 0.07 & 0 & 0.3 & Yes & No \\
\hline Egbert, ON, Canada & 21 May & 18 & 1.8 & No data & No data & 0 & 1.3 & Yes & No \\
\hline Egbert, ON, Canada & 22 May & 18 & 1.8 & No data & No data & 0 & 1.5 & Yes & No \\
\hline
\end{tabular}

${ }^{a}$ From DMPS/SMPS measurements. Max diameter is for the first day of growth only.

${ }^{b}$ From CIMS measurements. The maximum growth rate is calculated for the kinetic regime assuming an accommodation coefficient of 1 (Nieminen et al., 2010).

${ }^{\mathrm{c}}$ Change in total AMS mass (integrated over size distribution) from right before nucleation until growth stops at night.

effective saturation vapor pressure of organic species when using the Volatility Basis Set is found using the mass fractions of each component, not the mole fractions; therefore, $x_{i}$ in Eqs. (1) and (2) are taken as mass fractions in TOMAS.

Organic aerosol is assumed to have a $\Delta H_{\text {vap }}$ values based on Epstein et al. (2010). However, the model results are weakly sensitive to the $\Delta H_{\text {vap }}$ values because temperatures are generally within $15 \mathrm{~K}$ of $298 \mathrm{~K}$. The molecular weight of organics is assumed to be $200 \mathrm{~g} \mathrm{~mol}^{-1}$ for all bins. The density of organics is assumed to be $1400 \mathrm{~kg} \mathrm{~m}^{-3}$. Our results were not sensitive to reasonable changes in either of these assumptions. The initial dry particle composition is assumed to be half sulfate and half organics. The 9 event days used in this analysis were shown to have compositions close to this before nucleation. The model is only weakly sensitive to this initial composition, as we shall show by testing the sensitivity to the ability of organics partitioning to inorganics (described later). Freshly nucleated particles at $3 \mathrm{~nm}$ are assumed to be half sulfate and half organics. While this assumption is arbitrary, our results were not sensitive to this assumption. During all cases, we assume no exchange between the box and its surroundings (e.g. no dilution with free tropospheric air).

There are several uncertain inputs to the model. We will test the sensitivity of the model predictions to changes in these inputs across ranges of possible values. This will give us insight into the nature of SOA and ultrafine growth. These assumptions are:

1. The volatility (or volatility mixture) of the freshly formed secondary organic compounds. We test 7 volatilities and mixtures of volatilities ranging from $C^{*}=10^{-4}$ to $10^{-1} \mu \mathrm{g} \mathrm{m}^{-3}$. These cases are described in Table 2. SOA with $C^{*}=10^{0} \mu \mathrm{g} \mathrm{m}^{-3}$ would largely be in the aerosol phase for our cases (because ambi- ent SOA concentrations were generally around or above $1 \mu \mathrm{g} \mathrm{m}^{-3}$ ), but the conclusions are similar to $C^{*}=$ $10^{-1} \mu \mathrm{g} \mathrm{m}^{-3}$ cases (freshly nucleated aerosol showed little to no growth since nearly all new OA mass went to the accumulation mode), so it is not included. Also, the LV-OOA and SV-OOA distributions from Cappa and Jimenez (2010) were also tested for 15 April 2007. The results for the LV-OOA cases were similar to $C^{*}=$ $10^{-3} \mu \mathrm{g} \mathrm{m}^{-3}$ cases, and the results for the SV-OOA cases were similar to the various mixture cases.

2. The volatility (or volatility mixture) of the preexisting OA. We test 2 volatility cases for the preexisting OA, (1) all is effectively non-volatile $\left(C^{*}=\right.$ $10^{-5} \mu \mathrm{g} \mathrm{m}^{-3}$ ) and (2) it has a mixture of volatilities (the LOGTRI volatility distribution in Table 2). The $C^{*}=10^{-5} \mu \mathrm{g} \mathrm{m}^{-3}$ case allows us to assess partitioning of new SOA into a phase that has a different volatility than the condensing material.

3. The ability of OA to partition into aerosol sulfate and water. We test 2 cases: (1) OA does not effectively partition into sulfate and water ( $1 \%$ of sulfate and water mass contributes to organic-partitioning phase), or (2) OA does effectively partition into sulfate and water $(50 \%$ of sulfate and water mass contributes to the organic-partitioning phase).

4. The surface tension of the aerosol. We test values of, 0 , 0.025 and $0.05 \mathrm{~N} \mathrm{~m}^{-1}$. While the surface tension cannot be $0 \mathrm{~N} \mathrm{~m}^{-1}$, we include this case for the purpose of isolating the surface tension effect from other effects.

5. The accommodation coefficient. We test values of 1 and 0.05 . 
Table 2. Various assumptions of SOA volatilities used in TOMAS microphysics model.

\begin{tabular}{lcccccccc}
\hline & \multicolumn{7}{c}{$C^{*}$ values $\left[\mu \mathrm{g} \mathrm{m}^{-3}\right]$ at $298 \mathrm{~K}$} \\
\cline { 2 - 8 } & $10^{-5}$ & $10^{-4}$ & $10^{-3}$ & $10^{-2}$ & $10^{-1}$ & $10^{-0}$ & $10^{1}$ & $10^{-2}$ \\
\cline { 2 - 8 } Assumption name & \multicolumn{7}{c}{ Fraction of organics put into each $C^{*}$ bin } \\
\hline$C^{*}=10^{-4}$ & 0 & 1 & 0 & 0 & 0 & 0 & 0 & 0 \\
$C^{*}=10^{-3}$ & 0 & 0 & 1 & 0 & 0 & 0 & 0 & 0 \\
$C^{*}=10^{-2}$ & 0 & 0 & 0 & 1 & 0 & 0 & 0 & 0 \\
$C^{*}=10^{-1}$ & 0 & 0 & 0 & 0 & 1 & 0 & 0 & 0 \\
FLAT & 0 & 0 & 0.33 & 0.33 & 0.33 & 0 & 0 & 0 \\
TRI & 0.07 & 0.13 & 0.2 & 0.27 & 0.33 & 0 & 0 & 0 \\
LOGTRI & 0.03 & 0.06 & 0.13 & 0.26 & 0.52 & 0 & 0 & 0 \\
\hline
\end{tabular}

6. Particle-phase chemistry. We also test how particlephase chemistry in ultrafine particles could affect the growth of these particles. The details of this are described later.

We test every permutation of the above parameters to look at cross-parameter effects. Although none of these assumptions changes the total mass of SOA condensing in the simulations (since all volatilities are $C^{*}=10^{-1} \mu \mathrm{g} \mathrm{m}{ }^{-3}$ or less and OA concentrations are well above this during all events), they may each influence how much of the condensing mass goes to the ultrafine particles rather than larger particles.

In order to isolate the effect of organic volatility on the growth of ultrafine particles during the 9 event days, we constrain the box model inputs with measurements. The initial size distribution for each simulation is taken from observations at each site just prior to the nucleation event. Figure 1 shows the measured nucleation rate, the sulfuric acid concentration and the SOA formation rate used for inputs to the TOMAS box model for all the Hyytiälä 10 April 2007 simulations. The model-input nucleation rates as a function of time are derived from the SMPS data using the method of Dal Maso et al. (2005). The nucleated particles are added to the model at $3 \mathrm{~nm}$, the lower limit of the DMPS/SMPS detection. For simulations of the Hyytiälä events, gas-phase sulfuric acid concentrations are specified in the model based on the CIMS measurements. For the simulations of the Egbert events, sulfuric acid is added to the gas phase based on the mass change in sulfate concentrations measured by the AMS (the sulfuric acid then condenses onto the particles in TOMAS such that the sulfate masses in the model will match AMS observations). Since nucleation rates are derived from the SMPS data, sulfuric acid vapor concentrations are not used to predict nucleation rates. Organic material is initially formed in the gas phase (particle-phase chemistry discussed later) using the change in aerosol organic mass concentrations measured by the AMS with time. Since all SOA formed has a volatility of $10^{-1} \mu \mathrm{g} \mathrm{m}^{-3}$ or less and total organic concentrations are generally much larger than
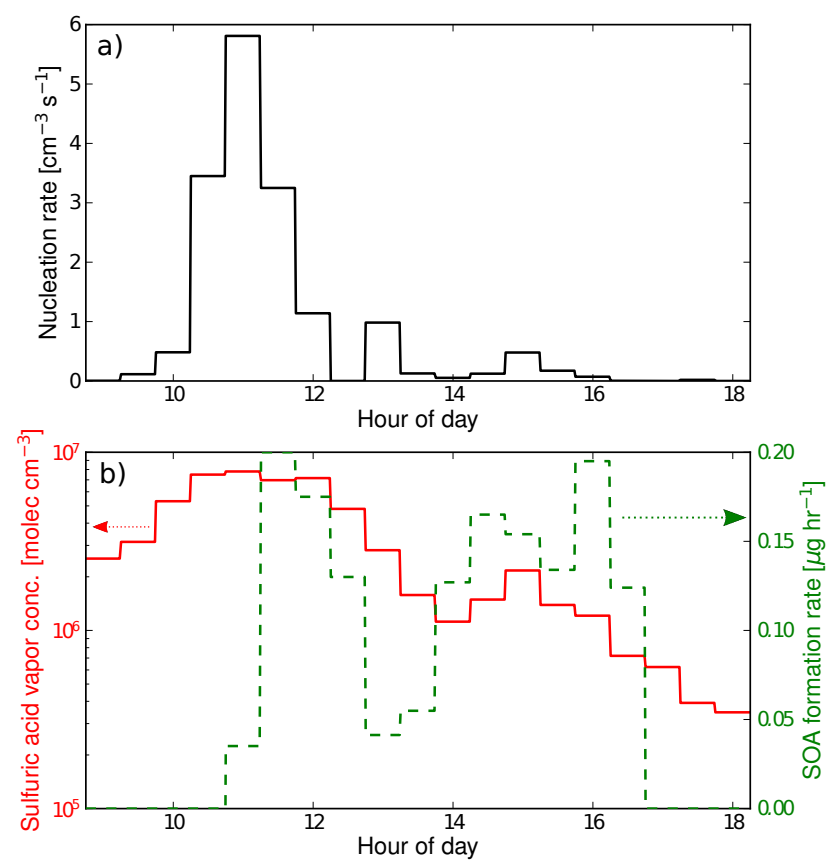

Fig. 1. (a) Nucleation rate and (b) the sulfuric acid vapor concentration and SOA formation rates used as inputs to the Hyytiälä 10 April 2007 box-model simulations. Nucleation rates are derived from SMPS data, sulfuric acid concentrations are from CIMS and the SOA mass formation rates are derived from AMS data. See text for details.

$10^{-1} \mu \mathrm{g} \mathrm{m}^{-3}$, nearly all of the freshly formed organic vapors will condense to the aerosol phase to form SOA mass. Thus, we are able to tightly constrain our total SOA mass formation without the uncertainties associated with VOC emissions and chemical yields.

Data-constrained model simulations can suffer due to noise in the data. Specifically, during the growth period of the ultrafine aerosols for the 9 events, the AMS-measured total concentrations of sulfate and organics generally increase 
with time, but there are some intervals when the observed mass of one of the species decreases slightly. Rather than removing mass from the simulation, we set the net addition of mass to 0 for this time period. This has a minimal affect on the total net condensation over the course of the events. Therefore, through use of the AMS, SMPS/DMPS and CIMS data, we constrain the initial aerosol size distribution, the nucleation rates and the total mass condensation rates of sulfate and organics to the model. The size distribution predicted by the model, however, will vary between simulations with different volatility, surface-tension and accommodation-coefficient assumptions.

Additionally, we explore the potential effects of particlephase chemistry creating low-volatility products (which could be representative of, for example, salt formation or oligomerization) in the freshly nucleated particles. We perform an additional set of simulations where organic material, regardless of its gas-phase volatility, is transformed to a saturation concentration to $10^{-5} \mu \mathrm{g} \mathrm{m}^{-3}$ upon entering particles smaller than $40 \mathrm{~nm}$. This is a simple first approximation of surface-limited particle-phase reactions (reactive uptake) in the freshly nucleated particles. The choice of volatility and size cut-off is arbitrary, but will demonstrate how particlephase chemistry could facilitate rapid growth of ultrafine particles.

\subsection{Model of kinetic evaporation in VDMPS}

To estimate the volatility (saturation concentration, $C^{*}$ ) of evaporating particles in the VDMPS, we use a model of kinetic evaporation (Riipinen et al., 2010). We model evaporation of nucleation- and Aitken-mode particles that undergo a step change from ambient temperature to $280^{\circ} \mathrm{C}$ for $1 \mathrm{~s}$, corresponding to the temperature and residence time in the heating section of the VDMPS (see Riipinen et al., 2011). The particles are modeled with two monodisperse modes whose diameters are assumed to be equal the geometric numbermean diameters averaged over the nucleation mode growth period (Fig. 2). The number concentrations in each mode are taken as the total number concentrations integrated over each mode (from lognormal fits of the distribution) averaged over the growth period. The particles are assumed to have a single saturation concentration, $C^{*}$ (at $298 \mathrm{~K}$ ). We repeat simulations varying $C^{*}$ until we find the $C^{*}$ value that gives the best prediction (to 2 significant figures) of the final size of the nucleation-mode particles measured after heating. We assume that the aerosol is in equilibrium with the gas phase initially. We assume a heat of vaporization $\left(\Delta H_{\mathrm{vap}}\right)$ of $80 \mathrm{~kJ} \mathrm{~mol}^{-1}$ for all cases. While this value of $\Delta H_{\mathrm{vap}}$ might be on the low end of the certainty range for low-volatility organics (Epstein et al., 2010), it results in higher inferred $C^{*}$ values than if we used a higher $\Delta H_{\text {vap }}$ value. This is consistent with our aim of determining an upper bound for the nucleation-mode volatility. The molecular masses and densities of the organic constituents are assumed to be the same as
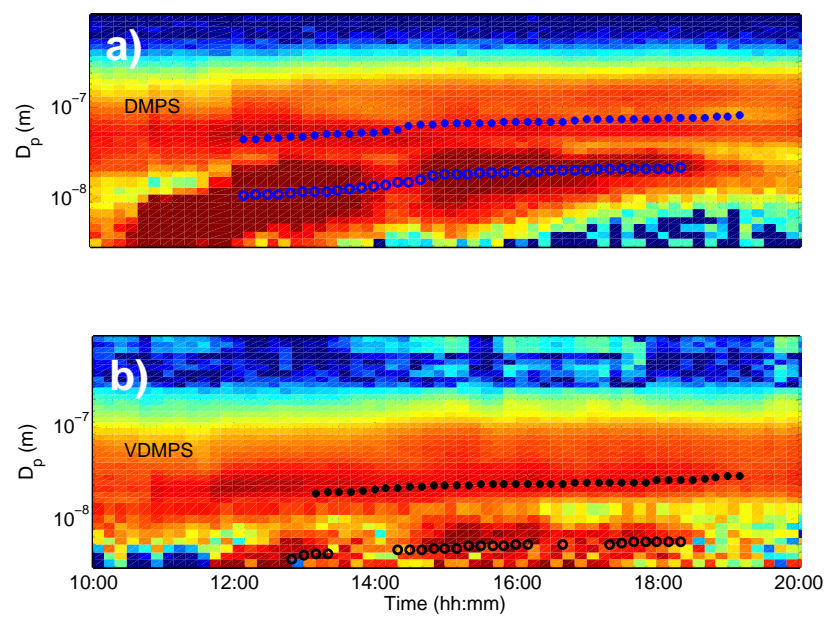

Fig. 2. Timeseries of the aerosol size distribution with time measured by the (a) DMPS and (b) VDMPS on 10 April 2007 in Hyytiälä. Aerosols in VDMPS were heated to $280^{\circ} \mathrm{C}$ for $1 \mathrm{~s}$ before measurement. The blue and black markers denote the geometric number-mean diameters of the Aitken and nucleation modes for each size scan. These number-mean diameters are averaged over the time of the nucleation event and used as inputs to the $C^{*}$ fit in the kinetic evaporation model.

in the box model simulations. We assume an accommodation coefficient of 0.05 or 1.0. In particular, the low accommodation coefficient, similar to $\Delta H_{\mathrm{vap}}$, biases us towards higher $C^{*}$ values. We test three different surface tensions, namely $0,0.05$ and $0.1 \mathrm{~N} \mathrm{~m}^{-1}$.

There are at least two crucial assumptions in the model making the obtained volatility value more approximate than exact. First, it is clear that the aerosol contains material with many different volatilities. However, with only one temperature point it is extremely difficult to constrain any distribution of volatilities from the measurements. Second, as with all other instruments that use heat to evaporate aerosol, we cannot rule out the possibility that the applied heat induces chemical transitions, such as pyrolysis reactions, in the aerosol. The volatility results from the VDMPS should thus be treated with caution and interpreted as a supporting set of results for the box-model simulations. In all, we analyze 8 nucleation events observed at Hyytiälä during spring 2007 with both DMPS and VDMPS systems with the evaporation model. These are listed in Table 1.

\section{Results}

\subsection{Simulation of growth during new-particle formation events}

\subsubsection{Gas-phase chemistry only}

Initially we will explore how the volatility of SOA affects the growth of freshly nucleated particles in cases where 

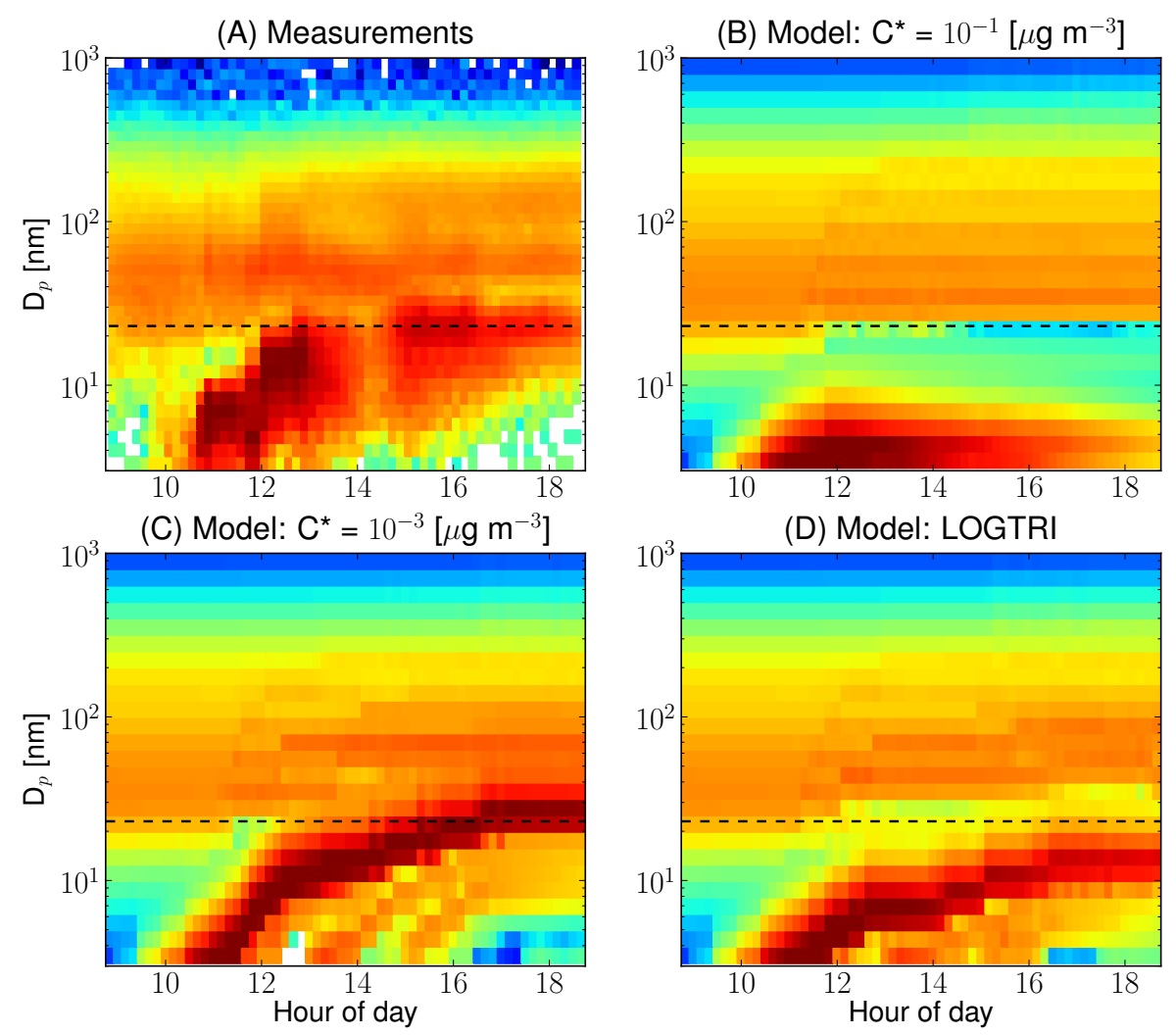

Fig. 3. Comparison of model-predicted growth of nucleated aerosol to measurements on 10 April 2007 in Hyytiälä. Panel (a) is the measured $d N / d \log D_{\mathrm{p}}$ timeseries. Panels (b-d) are the simulated $d N / d \log D_{\mathrm{p}}$ timeseries with condensing volatility distributions of $C^{*}=$ $10^{-1}, C^{*}=10^{-3}$ and LOGTRI, respectively. Surface tension was $0.025 \mathrm{~N} \mathrm{~m}^{-1}$, the accommodation coefficient was 1 , the pre-existing SOA had $C^{*}=10^{-5} \mu \mathrm{g} \mathrm{m}^{-3}$ and SOA does not partition into sulfate and water for these simulations. For comparison between the modelled cases and the measurements, the black dashed horizontal line in each figure denotes maximum diameter of the nucleation mode measured to during the event.

gas-phase chemistry forms low-volatility and semi-volatile compounds but no subsequent particle-phase chemistry occurs (particle-phase chemistry is explored in the next subsection). An example of the output of the TOMAS box model is shown in Fig. 3, which shows the measured size distribution on 10 April 2007 in Hyytiälä by the DMPS (panel a) along with the simulated size distributions from three different volatility cases for the freshly formed SOA $\left(C^{*}=10^{-1}\right.$, $C^{*}=10^{-3}$, LOGTRI) when assuming the surface tension was $0.025 \mathrm{~N} \mathrm{~m}^{-1}$, the accommodation coefficient was 1 , the pre-existing SOA had $C^{*}=10^{-5} \mu \mathrm{g} \mathrm{m}^{-3}$ and that SOA does not readily partition into sulfate and water. The measured size of the nucleation mode at the end of the first day is denoted by the black dashed horizontal line in each panel. Panel (b) corresponds to the case where semi-volatile organics are formed in the gas phase with $C^{*}=10^{-1} \mu \mathrm{g} \mathrm{m}^{-3}$. When nucleation occurs, the nucleated particles do no grow appreciably and are eventually lost through evaporation and coagulation. There appears to be initial growth to about 5-8 nm before these particles shrink due to a combination of a weakening source of gas-phase organics and surface tension. In panel (c), corresponding to $C^{*}=10^{-3} \mu \mathrm{g} \mathrm{m}^{-3}$, the freshly nucleated particles do grow appreciably, reaching sizes of about $28 \mathrm{~nm}$ (just beyond measured size distribution). In panel (d), corresponding to the case where the freshly formed SOA has a LOGTRI volatility distribution, the freshly nucleated particles grow to a size just smaller than the observations. The reasons for the different simulated growth patterns are explored below.

Figure 4 shows scatter plots of the simulated versus measured final diameter (at the end of the day) for the nucleation mode on all 9 event days. All simulation results in Fig. 4 are for cases where pre-existing aerosol has a saturation vapor pressure of $10^{-5} \mu \mathrm{g} \mathrm{m}^{-3}$ and organics do not readily partition into sulfate and water. The various panels show results for cases assuming different surface tensions and the accommodation coefficients. The cases with lower volatility $\left(C^{*}=10^{-4}\right.$ and $\left.10^{-3} \mu \mathrm{g} \mathrm{m}^{-3}\right)$ on average predict growth well except when the accommodation coefficient is 0.05 (panels $\mathrm{c}$ and $\mathrm{d}$ ), where they slightly underpredict the observed growth. All cases with high-volatility SOA $\left(C^{*}=10^{-1} \mu \mathrm{g} \mathrm{m}^{-3}\right)$ underpredict the growth. The 

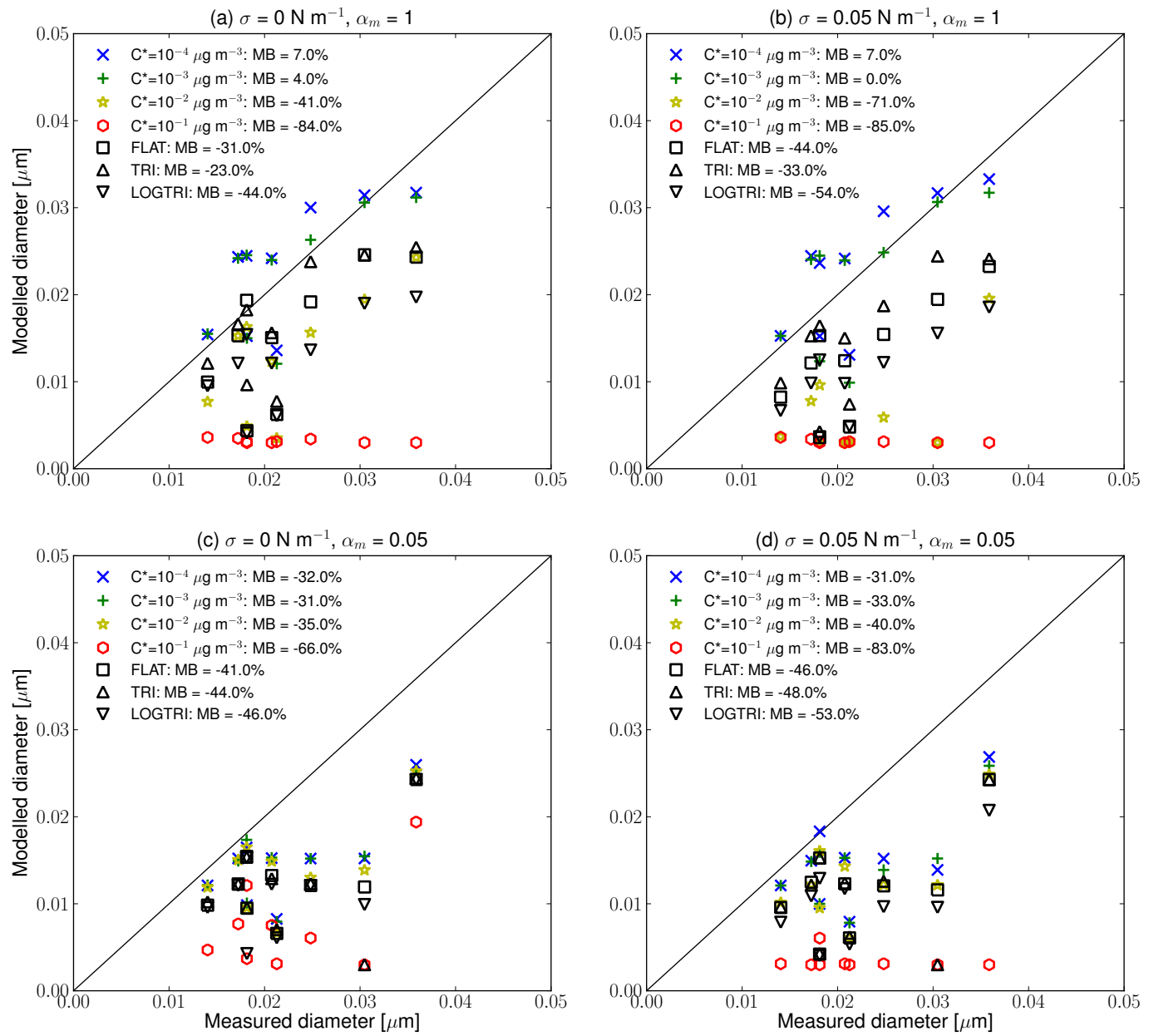

Fig. 4. Comparison of the simulated diameter to measured diameter of the nucleation mode after SOA condensation has stopped for the 7 events at Hyytiälä and Egbert. All simulations assumed that pre-existing organics have $C^{*}=10^{-5} \mu \mathrm{g} \mathrm{m}^{-3}$ and assumed that organics do not partition into sulfate and water. In each panel, different cases regarding the volatility distribution of organics are marked by different colors and symbol shapes. Panel (a) assumed surface tension is $0 \mathrm{~N} \mathrm{~m}^{-1}$ and accommodation coefficient is 1 . Panel (b) assumed surface tension is $0.05 \mathrm{~N} \mathrm{~m}^{-1}$ and accommodation coefficient is 1 . Panel (c) assumed surface tension is $0 \mathrm{~N} \mathrm{~m}^{-1}$ and accommodation coefficient is 0.05 . Panel (d) assumed surface tension is $0.05 \mathrm{~N} \mathrm{~m}^{-1}$ and accommodation coefficient is 0.05 . MB denotes the mean bias across the 9 events.

intermediate cases $\left(C^{*}=10^{-2} \mu \mathrm{g} \mathrm{m}^{-3}\right.$ and the various mixtures) tend to slightly underpredict growth when surface tension is low, and significantly underpredict growth when surface tension is higher.

We found three factors that can prevent ultrafine particles from growing effectively: (1) the smaller particles can reach equilibrium with the gas phase more quickly than larger particles (Meng and Seinfeld, 1996), thus the $x_{i}$ values for the condensing species can be higher in the smaller particles and the growth of ultrafines is slowed relative to the larger particles ("equilibrium effect"), (2) the surface tension increases the effective saturation concentration of smallest particles and the growth of ultrafines is slowed or reversed ("surfacetension effect"), and (3) reducing the accommodation coefficient slows mass transfer to the ultrafine particles more than accumulation-mode particles ("accommodation coeffi- cient effect"). However, lowering the accommodation coefficient could also help ultrafine growth in some cases because gas-phase concentrations would increase during periods of gas-phase SOA production.

The equilibrium effect is highlighted in Fig. 5. This figure shows the simulated condensational driving force $\left(C_{i, \infty}-\right.$ $\left.C_{i, \text { eff }}^{*}\right)$ and $x_{i}$ for volatility bins $C^{*}=10^{-4}, 10^{-3}, 10^{-2}$ and $10^{-1} \mu \mathrm{g} \mathrm{m}^{-3}$ as a function of particle size and time on 10 April 2007 in Hyytiälä. In Fig. 5, the freshly formed SOA has the LOGTRI volatility distribution, the pre-existing OA had a volatility of $C^{*}=10^{-5} \mu \mathrm{g} \mathrm{m}^{-3}$, the surface tension was 0 and the accommodation coefficient was 1 . Initially, the mass fractions, $x_{i}$, for $C^{*}$ bins $10^{-4}$ through $10^{-1} \mu \mathrm{g} \mathrm{m}{ }^{-3}$ are 0 for all sizes (panels e-h); however, once the gas-phase production of SOA and condensation starts, $x_{i}$ increases the most rapidly for the smallest particles, which increases $C_{i, \text { eff }}^{*}$ 

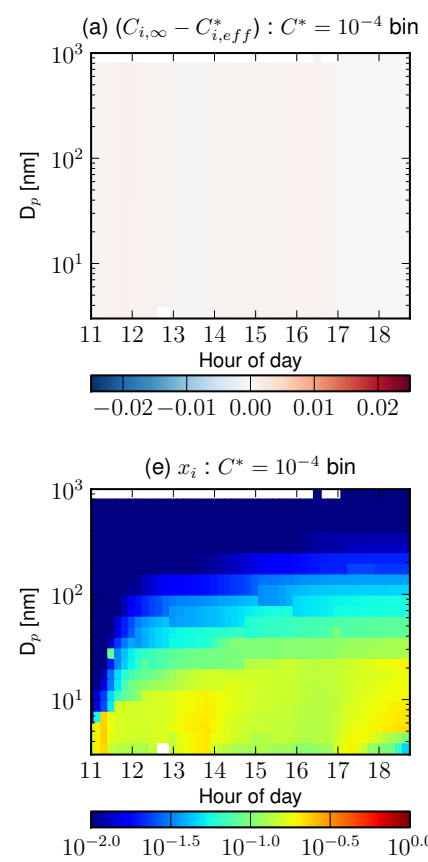

(b) $\left(C_{i, \infty}-C_{i, e f f}^{*}\right): C^{*}=10^{-3}$ bin

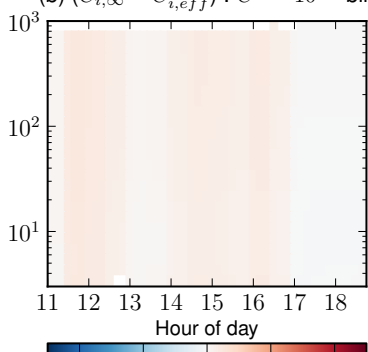

$\begin{array}{cccc}-0.02-0.01 & 0.00 & 0.01 & 0.02\end{array}$

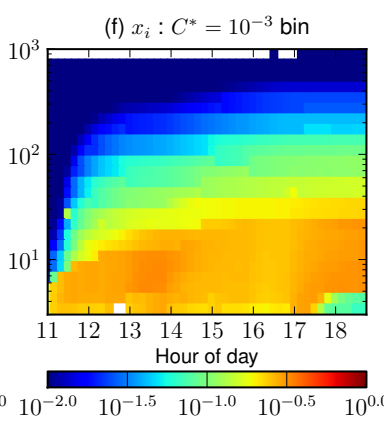

(c) $\left(C_{i, \infty}-C_{i, e f f}^{*}\right): C^{*}=10^{-2}$ bin

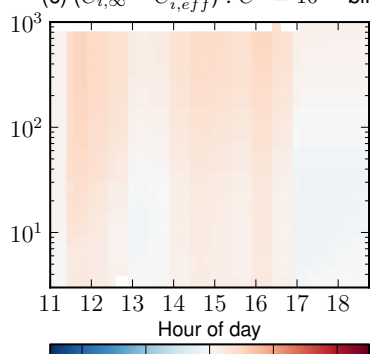

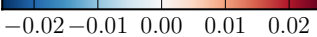

(g) $x_{i}: C^{*}=10^{-2}$ bin

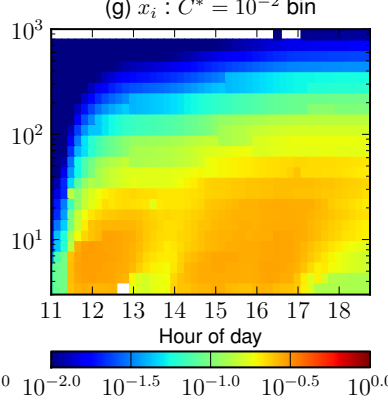

(d) $\left(C_{i, \infty}-C_{i, e f f}^{*}\right): C^{*}=10^{-1}$ bin
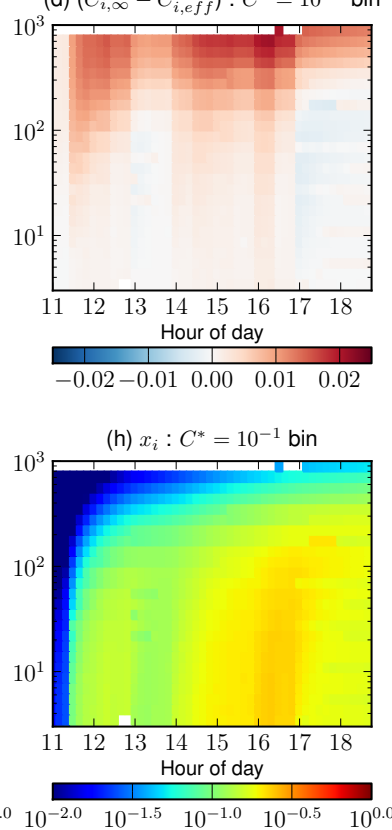

Fig. 5. Demonstration of how the equilibrium effect can inhibit ultrafine particle growth for Hyytiälä on 10 April 2007. Panels (a-d) show the condensational driving force $\left(C_{i, \infty}-C_{i, \text { eff }}^{*}\right)\left[\mu \mathrm{g} \mathrm{m}^{-3}\right.$ ] as a function of aerosol size and time for the $C^{*}=10^{-4}, 10^{-3}, 10^{-2}$ and $10^{-1}$ $\left[\mu \mathrm{g} \mathrm{m}^{-3}\right.$ ] volatility bins for the simulation where pre-existing SOA has $C^{*}=10^{-5}\left[\mu \mathrm{g} \mathrm{m}^{-3}\right.$ ], freshly formed SOA has a LOGTRI volatility distribution, SOA does not readily partition into sulfate and water, the surface tension is $0 \mathrm{~N} \mathrm{~m}^{-1}$, and the accommodation coefficient is 1 . Panels (e-h) show the mass mixing ratio ( $x_{i}$, note that the volatility basis set uses mass mixing ratios rather than molar mixing ratios) as a function of aerosol size and time for the same simulation.

for these small particles relative to the $C_{i, \text { eff }}^{*}$ for the larger particles. This does not affect the size dependence of the condensational driving force for the lowest volatilities (panels a-b) because $C_{i, \infty} \gg C_{i, \text { eff }}^{*}$ for all sizes. However, for the $C^{*}=10^{-2}$ and particularly for $10^{-1} \mu \mathrm{g} \mathrm{m}^{-3}$ bins, the condensational driving force is larger for the accumulation-mode particles compared to the ultrafine particles.

In both Figs. 4 and 5, the pre-existing SOA has a single volatility $\left(C^{*}=10^{-5} \mu \mathrm{g} \mathrm{m}^{-3}\right)$ and the condensing secondary-organic compounds have volatilities that are not in this volatility bin. This maximizes the ability of the equilibrium effect to slow the growth of freshly nucleated particles. On the other hand, we also did simulations where the pre-existing SOA contain a mixture of volatilities (LOGTRI). Table 3 summarizes the mean biases (averaged across the 9 event days) of all input cases. The equilibration effect is weaker when the LOGTRI distribution was used for pre-existing particles (rather than $C^{*}=10^{-5} \mu \mathrm{g} \mathrm{m}^{-3}$ ), and thus the values for the mean bias are larger for most cases. This difference highlights the importance of the pre-existing volatility distribution in the growth of ultrafine particles.

The surface-tension effect is illustrated in Fig. 6. Like Fig. 5, it shows the simulated condensational driving force and the mass fractions for various volatility bins on 10 April 2007 in Hyytiälä. However, Fig. 6 has a LOGTRI volatil- ity distribution for pre-existing organics and a surface tension of $0.05 \mathrm{~N} \mathrm{~m}^{-1}$. The difference in the pre-existing organic volatility distribution is reflected in comparing the initial values in Fig. 6e-h with Fig. $5 \mathrm{e}-\mathrm{h}$. In this simulation, $C_{i, \mathrm{eff}}^{*}$, is increased for the smallest particles because of the surface tension. This has a large effect on the condensational driving force for the $C^{*}=10^{-1} \mu \mathrm{g} \mathrm{m}^{-3}$ bin, where particles larger than about $10 \mathrm{~nm}$ have a strong net condensation throughout the event, but particles smaller than this experience net evaporation during some time periods. This effect is also present, but not as strongly, for the $C^{*}=10^{-2} \mu \mathrm{g} \mathrm{m}{ }^{-3}$ bin. The effect is even smaller, with little to no net evaporation of the smallest particles for the lowest volatility bins $\left(C^{*} \leq 10^{-3} \mu \mathrm{g} \mathrm{m}^{-3}\right)$ because $C_{i, \infty}>C_{i, \text { eff }}^{*}$ for all sizes. The surface-tension effects lead to a decrease in the mass fractions for the $C^{*}=10^{-1}$ and $10^{-2} \mu \mathrm{g} \mathrm{m}^{-3}$ bins for particle diameters smaller than about $20 \mathrm{~nm}$. This reduction of $x_{i}$ for these volatility bins decreases $C_{i, \text { eff }}^{*}$ for these volatility bins and somewhat dampens the evaporation of these particles. Because of the reduction of $x_{i}$ for the higher volatility bins, the lower volatility bins have an increase in $x_{i}$ at small diameters. This acts to slow the net condensation of the lower volatility compounds onto smaller sizes, but does not stop the condensation of these species altogether. 
Table 3. Mean bias (\%) across the 7 Hyytiälä and Egbert events for the various simulation assumptions. Mean biases less than $\pm 30 \%$ are shown in bold. The assumptions regarding the volatility distributions of freshly-formed secondary organic compounds are given by the different columns. Other model cases are varied in different rows.

\begin{tabular}{|c|c|c|c|c|c|c|c|c|c|c|}
\hline \multirow[b]{2}{*}{$\sigma$} & \multirow[b]{2}{*}{$\begin{array}{l}\alpha \\
{\left[\mathrm{N} \mathrm{m}^{-1}\right]}\end{array}$} & \multirow[b]{2}{*}{$\begin{array}{l}\text { Volatility of } \\
\text { Pre-existing organics }\end{array}$} & \multirow[b]{2}{*}{$\begin{array}{l}\text { Can partition } \\
\text { into sulfate/water? }\end{array}$} & \multicolumn{7}{|c|}{ Volatility of condensing SOA } \\
\hline & & & & $C^{*}=10^{-4}$ & $C^{*}=10^{-3}$ & $C^{*}=10^{-2}$ & $C^{*}=10^{-1}$ & FLAT & TRI & LOGTRI \\
\hline 0 & 1 & $C^{*}=10^{-5}$ & no & $7 \%$ & $4 \%$ & $-41 \%$ & $-84 \%$ & $-31 \%$ & $-23 \%$ & $-44 \%$ \\
\hline 0 & 1 & $C^{*}=10^{-5}$ & yes & $6 \%$ & $2 \%$ & $-30 \%$ & $-81 \%$ & $-27 \%$ & $-22 \%$ & $-41 \%$ \\
\hline 0 & 1 & LOGTRI & no & $43 \%$ & $42 \%$ & $23 \%$ & $-70 \%$ & $16 \%$ & $28 \%$ & $4 \%$ \\
\hline 0 & 1 & LOGTRI & yes & $32 \%$ & $29 \%$ & $4 \%$ & $-69 \%$ & $1 \%$ & $3 \%$ & $-10 \%$ \\
\hline 0 & 0.05 & $C^{*}=10^{-5}$ & no & $-32 \%$ & $-31 \%$ & $-35 \%$ & $-66 \%$ & $-41 \%$ & $-44 \%$ & $-46 \%$ \\
\hline 0 & 0.05 & $C^{*}=10^{-5}$ & yes & $-30 \%$ & $-31 \%$ & $-38 \%$ & $-56 \%$ & $-39 \%$ & $-40 \%$ & $-43 \%$ \\
\hline 0 & 0.05 & LOGTRI & no & $-18 \%$ & $-20 \%$ & $-22 \%$ & $-49 \%$ & $-27 \%$ & $-28 \%$ & $-31 \%$ \\
\hline 0 & 0.05 & LOGTRI & yes & $-23 \%$ & $-23 \%$ & $-27 \%$ & $-44 \%$ & $-29 \%$ & $-29 \%$ & $-31 \%$ \\
\hline 0.025 & 1 & $C^{*}=10^{-5}$ & no & $3 \%$ & $1 \%$ & $-56 \%$ & $-85 \%$ & $-38 \%$ & $-30 \%$ & $-48 \%$ \\
\hline 0.025 & 1 & $C^{*}=10^{-5}$ & yes & $6 \%$ & $2 \%$ & $-34 \%$ & $-83 \%$ & $-34 \%$ & $-25 \%$ & $-43 \%$ \\
\hline 0.025 & 1 & LOGTRI & no & $36 \%$ & $37 \%$ & $-3 \%$ & $-84 \%$ & $2 \%$ & $10 \%$ & $-7 \%$ \\
\hline 0.025 & 1 & LOGTRI & yes & $29 \%$ & $26 \%$ & $-5 \%$ & $-78 \%$ & $-4 \%$ & $-2 \%$ & $-20 \%$ \\
\hline 0.025 & 0.05 & $C^{*}=10^{-5}$ & no & $-31 \%$ & $-32 \%$ & $-38 \%$ & $-75 \%$ & $-48 \%$ & $-42 \%$ & $-51 \%$ \\
\hline 0.025 & 0.05 & $C^{*}=10^{-5}$ & yes & $-30 \%$ & $-30 \%$ & $-40 \%$ & $-67 \%$ & $-44 \%$ & $-44 \%$ & $-50 \%$ \\
\hline 0.025 & 0.05 & LOGTRI & no & $-19 \%$ & $-19 \%$ & $-24 \%$ & $-65 \%$ & $-30 \%$ & $-31 \%$ & $-35 \%$ \\
\hline 0.025 & 0.05 & LOGTRI & yes & $-24 \%$ & $-23 \%$ & $-31 \%$ & $-58 \%$ & $-36 \%$ & $-35 \%$ & $-41 \%$ \\
\hline 0.05 & 1 & $C^{*}=10^{-5}$ & no & $7 \%$ & $0 \%$ & $-71 \%$ & $-85 \%$ & $-44 \%$ & $-33 \%$ & $-54 \%$ \\
\hline 0.05 & 1 & $C^{*}=10^{-5}$ & yes & $8 \%$ & $2 \%$ & $-45 \%$ & $-84 \%$ & $-38 \%$ & $-31 \%$ & $-49 \%$ \\
\hline 0.05 & 1 & LOGTRI & no & $35 \%$ & $32 \%$ & $-31 \%$ & $-85 \%$ & $-8 \%$ & $3 \%$ & $-24 \%$ \\
\hline 0.05 & 1 & LOGTRI & yes & $30 \%$ & $19 \%$ & $-20 \%$ & $-81 \%$ & $-16 \%$ & $-9 \%$ & $-29 \%$ \\
\hline 0.05 & 0.05 & $C^{*}=10^{-5}$ & no & $-31 \%$ & $-33 \%$ & $-40 \%$ & $-83 \%$ & $-46 \%$ & $-48 \%$ & $-53 \%$ \\
\hline 0.05 & 0.05 & $C^{*}=10^{-5}$ & yes & $-30 \%$ & $-31 \%$ & $-39 \%$ & $-71 \%$ & $-45 \%$ & $-45 \%$ & $-50 \%$ \\
\hline 0.05 & 0.05 & LOGTRI & no & $-22 \%$ & $-22 \%$ & $-28 \%$ & $-76 \%$ & $-32 \%$ & $-30 \%$ & $-40 \%$ \\
\hline 0.05 & 0.05 & LOGTRI & yes & $-24 \%$ & $-24 \%$ & $-33 \%$ & $-66 \%$ & $-39 \%$ & $-37 \%$ & $-44 \%$ \\
\hline
\end{tabular}

The surface-tension effect appears in panels (b) and (d) of Fig. 4. Comparing panels (a) and (b), there is a downward shift in the modeled diameter due to slowed growth of the freshly nucleated particles. The two lowest volatility cases $\left(C^{*}=10^{-4}\right.$ and $\left.C^{*}=10^{-3} \mu \mathrm{g} \mathrm{m}^{-3}\right)$ were not greatly affected by the surface tension, while the other cases were more strongly affected.

Finally, the effect of the accommodation coefficient is shown in panels (c) and (d) of Fig. 4. By comparing panel (a) with panel (c) and comparing panel (b) with panel (d), we can see the isolated effects of decreasing the accommodation coefficient from 1 to 0.05 . For most volatility assumptions, the modeled diameter is reduced for the cases where the accommodation coefficient is 0.05 . This is because the accommodation coefficient reduces the mass transfer most strongly for ultrafine particles, thus slowing the net condensation for these particles more than for larger particles. However, the $C^{*}=10^{-2} \mu \mathrm{g} \mathrm{m}^{-3}$ cases show an increase in predicted nucleation-mode diameter when the accommodation coefficient is decreased from 1 to 0.05 for both surface tension values (compare panels $a$ and $b$ to $c$ and $d$ ). This increase in bias with decreasing accommodation coefficient is because the reduced accommodation coefficient slows the total net condensation from the gas phase and increases the gas-phase concentrations when SOA production is occurring.
This increase in $C_{i, \infty}$ allows $C_{i, \infty}$ to be greater than the $C_{i \text {,eff }}^{*}$ of the smaller particles for a larger fraction of the time so net condensation occurs to the small particles.

The nature of the accommodation coefficient is controversial (Kolb et al., 2010). One possibility is that what we are calling accommodation coefficient is really an uptake coefficient, which could include limitations in evaporation and particle-phase diffusion. For example, the uptake coefficient could be a proxy for condensed-phase diffusive limitations and be smaller for larger particles. In this case the uptake coefficient might be larger for the ultrafine particles, and this would enhance the growth of the ultrafine particles relative to larger particles. This scenario is not tested in this paper. Other factors, such as differences in surface composition, may also affect the accommodation/uptake coefficient as a function of size.

The mean bias across the 9 events for all combinations of simulated input cases is shown in Table 3. Sets of assumptions giving absolute values of biases of less than $30 \%$ are shown in bold. Generally, the assumption of lowvolatility condensing species $\left(C^{*} \leq 10^{-3} \mu \mathrm{g} \mathrm{m}^{-3}\right)$ generally agrees well with observations for most input cases. Some exceptions are (1) the growth is somewhat overpredicted when the pre-existing organics have the LOGTRI distribution and the accommodation coefficient is 1 and (2) the growth 

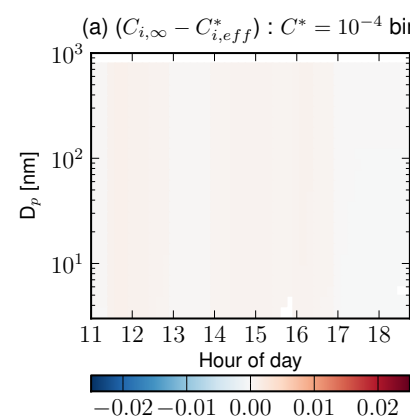

(e) $x_{i}: C^{*}=10^{-4} \mathrm{bin}$

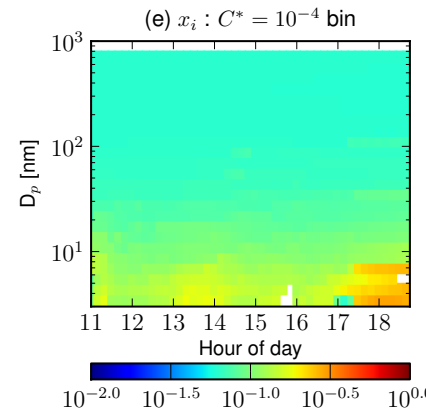

(b) $\left(C_{i, \infty}-C_{i, e f f}^{*}\right): C^{*}=10^{-3}$ bin

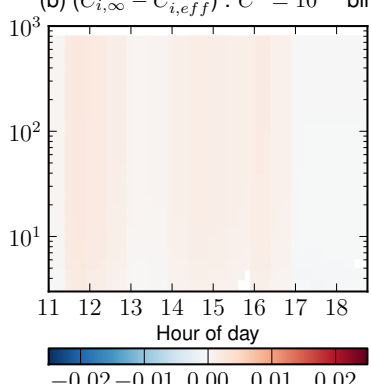

(f) $x_{i}: C^{*}=10^{-3}$ bin

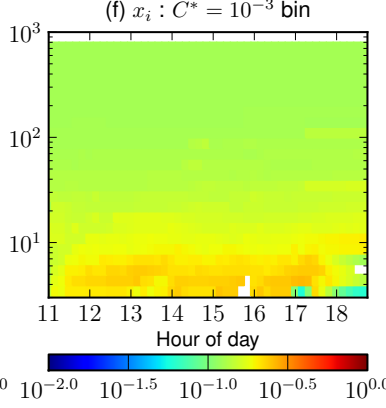

(c) $\left(C_{i, \infty}-C_{i, f f}^{*}\right): C^{*}=10^{-2}$ bin

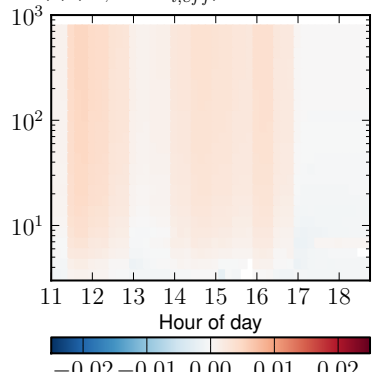

(g) $x_{i}: C^{*}=10^{-2}$ bin

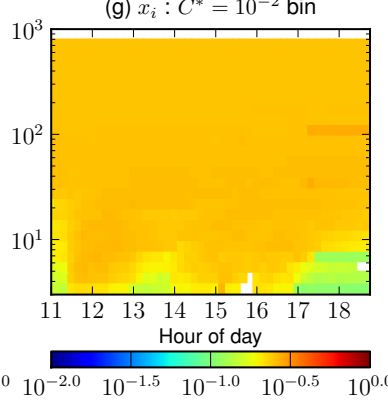

(d) $\left(C_{i, \infty}-C_{i, e f f}^{*}\right): C^{*}=10^{-1}$ bin

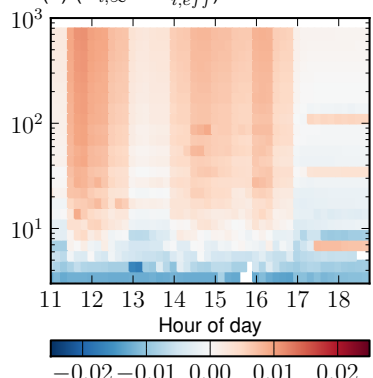

(h) $x_{i}: C^{*}=10^{-1}$ bin

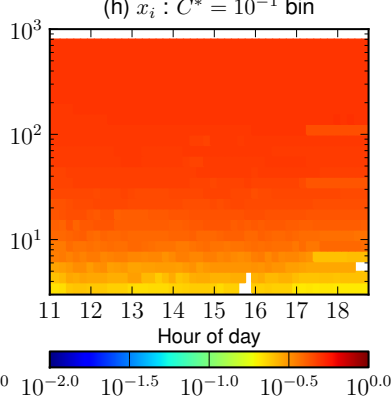

Fig. 6. Demonstration of how the surface tension effect can inhibit ultrafine particle growth for Hyytiälä on 10 April 2007. Panels (a-d) show the condensational driving force $\left(C_{i, \infty}-C_{i, \text { eff }}^{*}\right)\left[\mu \mathrm{g} \mathrm{m}^{-3}\right]$ as a function of aerosol size and time for the $C^{*}=10^{-4}, 10^{-3}, 10^{-2}$ and $10^{-1}\left[\mu \mathrm{g} \mathrm{m}^{-3}\right]$ volatility bins for the simulation where both pre-existing and freshly formed SOA has a LOGTRI volatility distribution, SOA does not partition into sulfate and water, the surface tension is $0.05 \mathrm{~N} \mathrm{~m}^{-1}$, and the accommodation coefficient is 1 . Panels (e-h) show the mass mixing ratio $\left(x_{i}\right.$, note that the volatility basis set uses mass mixing ratios rather than molar mixing ratios) as a function of aerosol size and time for the same simulation.

is somewhat underpredicted when the pre-existing organics have a $C^{*}=10^{-5} \mathrm{\mu g} \mathrm{m}^{-3}$ and the accommodation coefficient is 0.05 . The cases where the condensing species have $C^{*}=10^{-2} \mu \mathrm{g} \mathrm{m}^{-3}$ or the mixtures of volatilities (FLAT, TRI and LOGTRI) are most likely to agree with the observations when the surface tension is 0 . They also are more likely to agree when the accommodation coefficient is 1 and when the pre-existing organics contain the LOGTRI mixture of volatilities (rather than the single low-volatility $C^{*}=10^{-5}$ ). The likelihood of agreement does not depend greatly on whether or not the organics can partition into a sulfate/water phase in these analyses. The condensation of $C^{*}=10^{-1} \mu \mathrm{g} \mathrm{m}{ }^{-3}$ does not give good agreement for any simulation. This is because the growth inhibitions from equilibrium, surface-tension and accommodation-coefficient effects are too big for the small particles to grow when volatilities are this high.

Simulations were also performed on 15 April 2007 in Hyytiälä using the LV-OOA and SV-OOA volatility distributions presented by Cappa and Jimenez (2010) based on measurements in Mexico City during the MILAGRO campaign (not shown). The results for LV-OOA were similar to the $C^{*}=10^{-3} \mu \mathrm{g} \mathrm{m}^{-3}$ results, and the SV-OOA results were similar to the results from the various mixtures of volatilities (LOGTRI etc.). This has two potential implications: (1) since the analysis of volatilities in Cappa and Jimenez (2010) was done on accumulation-mode aerosol, this shows that the volatilities in the ultrafine particles may not be very different from the accumulation mode, and (2) this shows that aged organic aerosol volatilities in Mexico City might not be so different from the volatilities of aerosol in Northern forested regions.

The surface tension of the aerosols cannot be 0 . It is likely that mixtures of aerosol organics have surface tensions in the range of $0.02-0.05 \mathrm{~N} \mathrm{~m}^{-1}$ (Alvarez et al., 1997; Egemen et al., 2000), and when mixed with water the surface tension of the particles can approach $0.07 \mathrm{~N} \mathrm{~m}^{-1}$. For some solid phases, the surface tensions may even be higher. Our analysis showed that when surface tension is $0.025-0.05 \mathrm{~N} \mathrm{~m}^{-1}$, the cases with low-volatility $\left(C^{*} \leq 10^{-3} \mu \mathrm{g} \mathrm{m}^{-3}\right)$ condensing SOA agree best with the observations. There are still many input cases where $C^{*}=10^{-2} \mu \mathrm{g} \mathrm{m}^{-3}$ or the mixtures of volatilities also gave good agreement, so these cannot be ruled out. Regardless, this suggests that on these nucleation days, the condensing SOA contained a large fraction of low-volatility $\left(C^{*} \leq 10^{-3}-10^{-2} \mu \mathrm{g} \mathrm{m}^{-3}\right)$ material. The SOA will, of course, have some range of volatilities; however, a significant fraction must be lower volatility than $10^{-2} \mu \mathrm{g} \mathrm{m}^{-3}$ (at least in the ultrafine particles). Higher surface tensions would generally require even lower volatilities. These upper-bound volatilities are about 30-300 times more 
volatile than the results presented by a related study, Kulmala et al. (1998), using a similar technique. Some possible reasons for the differences are: (1) In Kulmala et al. (1998) only one species (along with water) is allowed to condense in each simulation; however, in the present study, each simulation include sulfuric acid condensation and at least one organic species, (2) Kulmala et al. (1998) had a lower diameter cutoff of $2 \mathrm{~nm}$, while the current study has a lower diameter cutoff of $3 \mathrm{~nm}$, and (3) Kulmala et al. (1998) did not nest the range of assumptions that would affect aerosols activity. Also, our results indicate the maximum volatility of the condensing molecules could in theory have to be able to condense on the nucleation mode. It is well possible that the actual compounds are even less volatile than the conservative estimates we are giving. In the next subsection, we explore the possibility of particle-phase reactions lowering the volatility of SOA in the ultrafine particles.

\subsubsection{Aerosol-phase chemistry}

It is possible that the volatility of SOA is being lowered by reactions within the aerosol phase. If the aerosol-phase reactions are surface-area limited, act on fast timescales and are not size/composition dependent, the results will be identical to what was found in the above analysis of gas-phase chemistry. In this scenario, the aerosol-phase reactions would likely have to produce compounds with saturation vapor pressures, $C^{*}$, less than about $10^{-3} \mu \mathrm{g} \mathrm{m}^{-3}$. Because of the aerosol-phase reactions, the initial volatilities of the species in the gas phase would not need to be this low. However, if particle-phase reactions are slower, volume limited and also not size/composition dependent, the net condensation will favor growth of larger particles and inhibit growth of the smallest particles relative to the gas-phase reactions. This growth is proportional to the volume or mass of the particle and will likely not reproduce the growth of the freshly nucleated particles (Riipinen et al., 2011).

Particle-phase chemistry has to be composition dependent, but the details of the various chemical mechanisms are still uncertain (Hallquist et al., 2009; Wang et al., 2010; Lim et al., 2010; Smith et al., 2010). Because aerosol composition is often very different between freshly nucleated particles and larger pre-existing particles, it is then possible that the rate of particle-phase chemistry depends on particle size. If the particle-phase chemistry creating low-volatility compounds is more favorable in larger particles, the growth of freshly nucleated particles would be inhibited relative to the gas-phase chemistry results and would not reproduce the observed ultrafine growth. If, however, the particle-phase chemistry is favored in the small particles, the growth of the freshly nucleated particles could proceed more rapidly compared to the case where gas-phase chemistry creates the low-volatility compounds.
Figure 7 shows results from an additional set of simulations exploring the possibility of particle-phase chemistry creating low volatility organics in the ultrafine particles only. In these simulations, the volatility of all organics in particles lower than $40 \mathrm{~nm}$ are instantly lowered to $C^{*}=10^{-5} \mu \mathrm{g} \mathrm{m}{ }^{-3}$. The choices of cut-off diameter, instantaneous reaction and volatility are arbitrary but they illustrate the potential implications of particle-phase chemistry in the freshly nucleated particles. If finite reaction rate constants were used, the results of these tests could change. This additional detail is left to future work; however, the main conclusions regarding the necessary low volatilities of the reaction products would not change. In these simulations we assume that organics do not readily partition into sulfate and water and that the volatility of the pre-existing particles is $C^{*}=10^{-5} \mu \mathrm{g} \mathrm{m}^{-3}$. The various symbols show the initial volatility of freshly formed SOA in the gas phase (before undergoing particle-phase chemistry). Panel (a) shows results with no surface tension and an accommodation coefficient of 1 . In these cases, the higher volatility assumptions $\left(C^{*}=10^{-2}\right.$ and $10^{-1} \mu \mathrm{g} \mathrm{m}^{-3}$ and the mixtures) overpredict growth. This is because SOA that initially condenses onto particles larger than $40 \mathrm{~nm}$ can reevaporate and have multiple chances of condensing onto the sub- $40 \mathrm{~nm}$ particles. Once in sub- $40 \mathrm{~nm}$ particles, the SOA reacts to becomes effectively non-volatile. The lower volatility $\operatorname{SOA}\left(C^{*}=10^{-4}\right.$ and $\left.10^{-3} \mu \mathrm{g} \mathrm{m}^{-3}\right)$ does not readily reevaporate from the larger particles, thus the results are similar to the gas-phase chemistry simulations earlier. Panel (b) shows the results for cases with a surface tension of 0 and an accommodation coefficient of 0.05 . The low accommodation coefficient slows down the re-evaporation of the all volatilities. This means that although the higher-volatility compounds led to overpredicted growth when the accommodation coefficient was 1 (panel a), all volatility cases result in predicted growth within $30 \%$ for the lower accommodation coefficient simulations. Raising the surface tension had no effect on the results since all particles smaller than $40 \mathrm{~nm}$ were effectively non-volatile $\left(C^{*}=10^{-5} \mu \mathrm{g} \mathrm{m}^{-3}\right)$.

The results in Fig. 7 show that with particle-phase chemistry in the ultrafine particles can lead to fast growth of freshly nucleated particles (greatly exceeding observed growth in some cases). However, like with most other cases described earlier, a significant fraction of the organic aerosol in the ultrafine particles needs volatilities less than about $10^{-3} \mu \mathrm{g} \mathrm{m}{ }^{-3}$.

\subsection{Upper bounds on volatility through kinetic evaporation in VDMPS}

In this section, we estimate the average volatility of the ultrafine aerosols from Volatility Differential Mobility Particle Sizer (VDMPS) data. Figure 2 shows the results of VDMPS analysis for 10 April 2007 in Hyytiälä. Panel (a) shows the measured DMPS timeseries without heating. The nucleation event starts around 11:00 and the nucleation mode grows to 

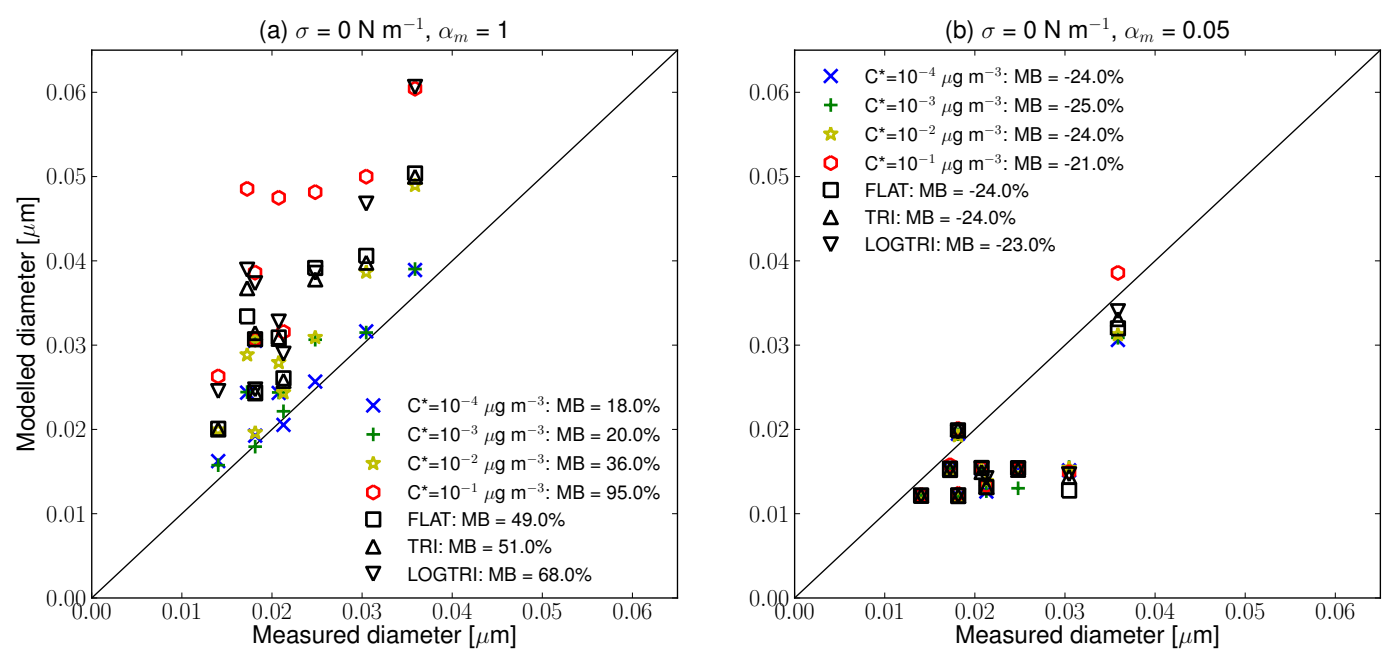

Fig. 7. Comparison of the simulated diameter to measured diameter of the nucleation mode after SOA condensation has stopped for the 7 events at Hyytiälä and Egbert. In these simulations OC that condenses onto particles with diameters smaller than $40 \mathrm{~nm}$ is instantly converted to a $C^{*}$ of $10^{-5} \mu \mathrm{g} \mathrm{m}^{-3}$ possibly representative of aerosol-phase chemistry. All simulations assumed that pre-existing organics have $C^{*}=10^{-5} \mu \mathrm{g} \mathrm{m}^{-3}$ and assumed that organics do not partition into sulfate and water. In each panel, different cases regarding the volatility distribution of organics are marked by different colors and symbol shapes. Panel (a) assumed surface tension is $0 \mathrm{Nm}^{-1}$ and accommodation coefficient is 1 . Panel (b) assumed surface tension is $0 \mathrm{~N} \mathrm{~m}^{-1}$ and accommodation coefficient is 0.05 . Changes in surface tension had no effect on these simulations due to the low volatility of the ultrafine particles. MB denotes the mean bias across the 9 events.

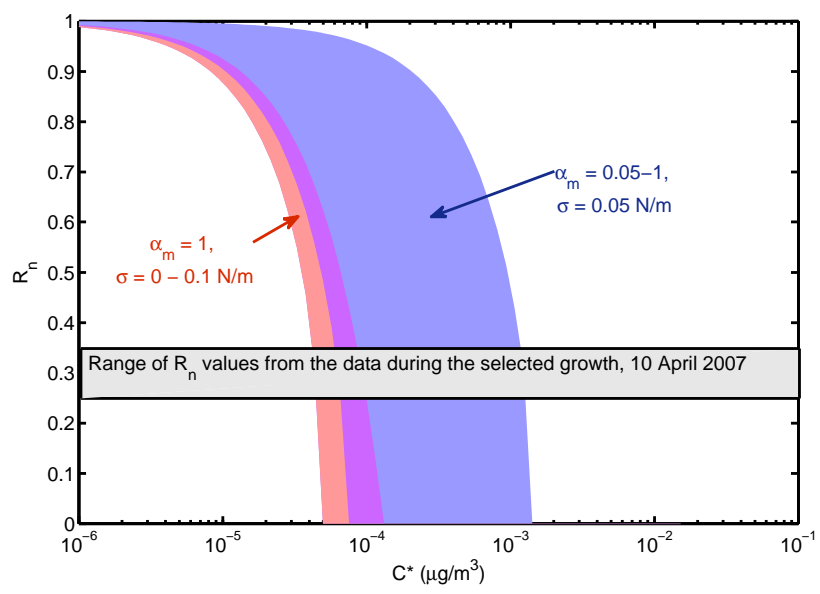

Fig. 8. Predicted $R_{n}\left(D_{\mathrm{p}, \text { VDMPS }} / D_{\mathrm{p}, \mathrm{DMPS}}\right)$ from the kinetic evaporation model as a function of $C^{*}$ for 10 April 2007. The blue shaded region shows the sensitivity to the accommodation coefficient $\left(\alpha_{m}\right)$ while the surface tension $(\sigma)$ is held fixed at $0.05 \mathrm{~N} \mathrm{~m}^{-1}$. The pink shaded region shows the sensitivity to the surface tension with the accommodation coefficient held fixed at 1 . The purple region is the overlap of the pink and blue regions. The gray box denotes the range of $R_{n}$ values measured by the VDMPS on 10 April 2007. The range of possible $C^{*}$ values is given by the overlap between the pink/blue areas with the gray box $\left(4.5 \times 10^{-5}-1.2 \times 10^{-3}\right)$.

about $20 \mathrm{~nm}$ by around 16:00 local winter time (UTC+2). Panel (b) shows the measured size distribution after $1 \mathrm{~s}$ of heating at $280^{\circ} \mathrm{C}$. The nucleation mode is clearly still present after heating, but has a maximum size less than $7 \mathrm{~nm}$.
We calculate the theoretical evaporation in the DMPS heating section as a function of aerosol $C^{*}$. Figure 8 shows the simulated ratio between the diameter after heating versus before heating $\left(R_{n}\right)$ as a function of the $C^{*}$ used in the evaporation mode. Figure 8 also shows the range of $R_{n}$ values determined from the experimental data on 10 April 2007 during the time period indicated in Fig. 2. By varying values of the mass accommodation coefficient and surface tension, we find the best-fit $C^{*}$ values are between $4.5 \times 10^{-5}$ and $1.2 \times 10^{-3} \mu \mathrm{g} \mathrm{m}^{-3}$. This very low volatility is necessary for the particle to not evaporate further (or evaporate entirely) during the heating.

The $C^{*}$ values corresponding to the best fits for the rest of the analyzed nucleation events in Hyytiälä are given in Table 4. Across all analyzed days, we find that in order to explain the difference in the geometric mean diameters of the particles with evaporation from nucleation mode, we need saturation concentrations less than $10^{-4}-10^{-3} \mu \mathrm{g} \mathrm{m}^{-3}$. This is consistent with the volatilities necessary to simulate the observed growth during nucleation events that we reported earlier. Although uncertainties in the accommodation coefficient $\left(\alpha_{\mathrm{m}}\right)$ and surface tension $(\sigma)$ can affect the best-fit $C^{*}$ value by over an order of magnitude for each case, all best-fit $C^{*}$ values were less than $3 \times 10^{-3} \mu \mathrm{g} \mathrm{m}^{-3}$.

As stated earlier in the model description, there are at least two simplifying assumptions in this analysis. First, we are approximating a range of volatilities in the aerosols with a single volatility. This is necessary given the single temperature of the VDMPS. Many of the aerosol species may have 
Table 4. The single-component saturation concentrations $C^{*}$ corresponding to the best fits between measured and modelled ratios between ambient (DMPS) and heated (VDMPS) particle diameters during a selection of atmospheric nucleation events in Hyytiälä, Finland.

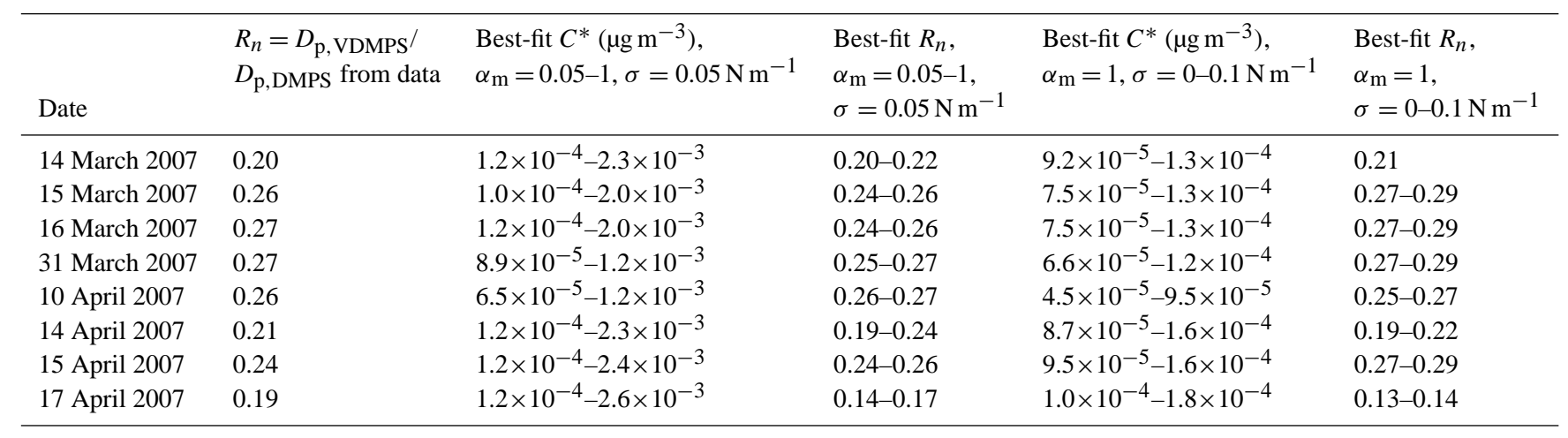

higher volatilities than the average volatility reported here; however, these must be balanced by species with even lower volatilities. The second assumption is that we do not account for any chemical changes occurring due to the heating of the aerosols to $280^{\circ} \mathrm{C}$ (e.g. pyrolysis). However, we feel that the results from the VDMPS strongly support the nucleation-mode growth calculations above - particularly as in their parallel analysis of the VDMPS data and AMS data from Hyytiälä, Raatikainen et al. (2010), saw no significant indications of pyrolysis. Another potentially complicating factor in the VDMPS analysis of the organic volatilities is the presence of sulfate in the nucleation mode. Previous work estimates that all aerosol sulfuric acid and ammonium sulfate in the ultrafine particles should be evaporated within $1 \mathrm{~s}$ in the VDMPS at $280^{\circ} \mathrm{C}$ (Ehn et al., 2007). However, interactions between inorganic and organic species (e.g. aminium sulfate) may cause changes in the evaporation temperature.

\section{Conclusions}

In this paper, we constrained the volatility of SOA in freshly nucleated aerosol in 13 nucleation/growth events at two remote continental sites using two independent methods. The first method involved simulating the growth of the freshly nucleated aerosols in a box model of aerosol microphysics that is constrained by observations. We found the SOA volatility ranges that allow this model to reproduce the measured growth of the nucleated particles. The second method involved modeling evaporation of aerosols in a Volatility Differential Mobility Particle Sizer (VDMPS) to determine the aerosol volatility required to match measured evaporation in the VDMPS. From both methods we found that the average saturation concentrations $\left(C^{*}\right)$ of organics in the aerosols likely needs to be around $10^{-3}-10^{-2} \mu \mathrm{g} \mathrm{m}^{-3}$ or less to facilitate growth of freshly nucleated particles starting at $3 \mathrm{~nm}$. If organics are condensing onto particles smaller than $3 \mathrm{~nm}$,

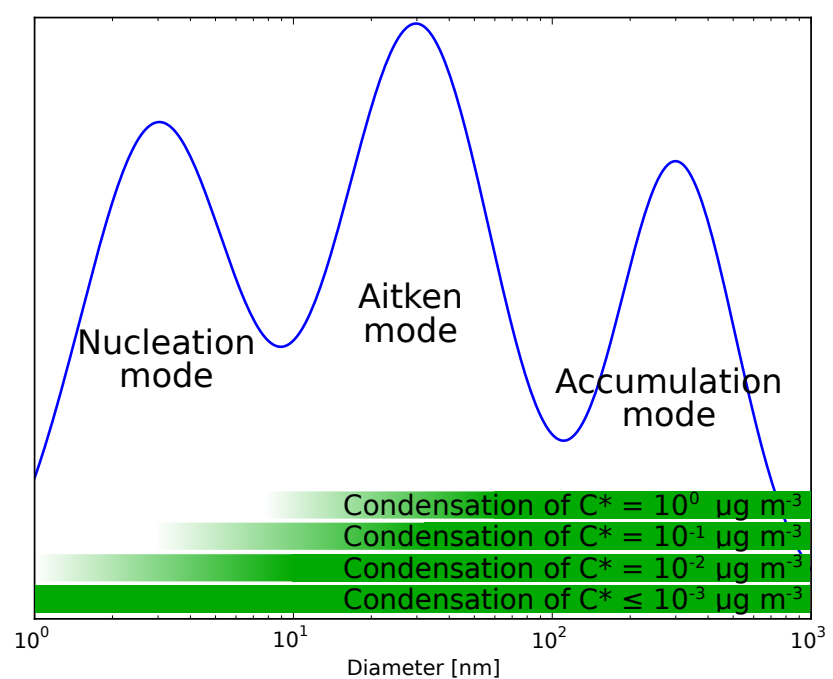

Fig. 9. Schematic demonstrating roughly where organic aerosol will net condense onto particles. The exact details of the lower-bound diameter of condensation depend greatly on the surface tension of the aerosol and the time-dependent activity (aerosol-phase mass or mole fractions in most SOA frameworks) of the condensing species; thus, the specific values in this figure should not be used as a reference. Lower volatility species will more readily condense onto (or partition into) freshly nucleated particles. The results of this study showed that SOA needs a saturation vapor concentration of less than $10^{-3}$ to $10^{-2} \mu \mathrm{g} \mathrm{m}^{-3}$ in order to grow freshly nucleated particles.

as shown to be likely by Riipinen et al. (2011), these saturation vapor concentrations would necessarily be even lower as suggested by Kulmala et al. (1998).

Along with testing the volatility of the condensing organics in the growth simulations, we also found our results to be sensitive to: (1) the assumed surface tension of the condensing organics, (2) the mass accommodation coefficient of the condensing organics, and (3) the volatility of the 
pre-existing organics. The results were not very sensitive to the ability of organics to partition into inorganics. For cases where the surface tension was unrealistically assumed to be zero, slightly higher volatility organics $\left(C^{*}=10^{-2} \mu \mathrm{g} \mathrm{m}^{-3}\right)$ or mixtures containing $50 \%$ or less low-volatility organics $\left(C^{*} \leq 10^{-3} \mu \mathrm{g} \mathrm{m}^{-3}\right)$ were more likely account for the growth of nucleated particles. Thus, our estimates are that $C^{*}=$ $10^{-2} \mu \mathrm{g} \mathrm{m}^{-3}$ is an absolute upper bound for these cases, but might not be realistic.

A sufficient quantity of organics with saturation concentrations less than $10^{-3}-10^{-2} \mu \mathrm{g} \mathrm{m}^{-3}$ may be difficult to make through gas-phase chemistry alone, but we did not address the likelihood of gas-phase chemistry producing these lowvolatility compounds (this has been addressed in a related paper, Donahue et al., 2011). We did, however, also test particle-phase chemistry in ultrafine particles as a source of low-volatility SOA. We found that this particle-phase chemistry in ultrafine particles can be even more effective for growing the ultrafine particles than when the low-volatility SOA is formed in the gas phase. However, this accelerated growth of ultrafine particles only occurs if the composition of ultrafine particles makes particle-phase chemistry more favorable in these particles than larger particles.

Regardless of the location of the organic chemistry that creates the lower-volatility compounds (gas phase versus aerosol phase), the lower-limit diameters for net condensation depend greatly on the volatility. Figure 9 is a schematic that demonstrates this. As was demonstrated in this paper by the model sensitivity cases, these lower-limit diameters depend greatly on the surface tension of the aerosol and the activity (aerosol-phase mole or mass fractions in most SOA frameworks) of the net-condensing species. Regardless, lower volatility compounds will more readily condense to freshly nucleated particles.

It is clear from these results that the SOA in the growing nucleation mode of the tested events contains large $(>50 \%)$ fractions of low-volatility $\left(C^{*} \leq 10^{-3}-10^{-2} \mu \mathrm{g} \mathrm{m}^{-3}\right)$ SOA. However, we are left with several important unresolved questions:

1. The two measurement locations tested here were dominated by biogenic SOA from northern forests. Are similar results found at other locations - particularly locations dominated by other sources of SOA?

2. These saturation vapor concentrations are lower than the volatilities of most of the identified individual SOA components. How are the volatilities becoming this low?

3. Can gas-phase oxidation alone produce a high enough concentration of low-volatility $\left(C^{*} \leq 10^{-3}-\right.$ $10^{-2} \mu \mathrm{g} \mathrm{m}^{-3}$ ) compounds to account for the observed growth, or is particle-phase chemistry required? We address this question in a related paper, Donahue et al. (2011).
4. If particle-phase chemistry is involved in creating the low-volatility compounds, what reactions are responsible, and might reaction rates be a strong function of aerosol size?

Answering these questions will be critical to understanding the connection between nucleation and ultrafine particles with $\mathrm{CCN}$ and climate.

Acknowledgements. JRP acknowledges support from NSERC Discovery Grant 371797-2009. IR acknowledgements support from the Camille and Henry Dreyfus Foundation and University of Helsinki funds. NMD acknowledges support from NSF CHE-1012293. Academy of Finland projects no. 211483, 211484 and 1118615,139656 are also gratefully acknowledged. Also funding via European Research Council through Advanced Grant ATMNUCLE is gratefully acknowledged.

Edited by: R. Krejci

\section{References}

Adams, P. J. and Seinfeld, J. H.: Predicting global aerosol size distributions in general circulation models, J. Geophys. Res., 107, 4370, doi:10.1029/2001JD001010, 2002.

Albrecht, B. A.: Aerosols, Cloud Microphysics, and Fractional Cloudiness, Science, 245, 1227-1230, 1989.

Allan, J. D., Alfarra, M. R., Bower, K. N., Coe, H., Jayne, J. T., Worsnop, D. R., Aalto, P. P., Kulmala, M., Hyötyläinen, T., Cavalli, F., and Laaksonen, A.: Size and composition measurements of background aerosol and new particle growth in a Finnish forest during QUEST 2 using an Aerodyne Aerosol Mass Spectrometer, Atmos. Chem. Phys., 6, 315-327, doi:10.5194/acp-6-315-2006, 2006.

Alvarez, E., Vazquez, G., SanchezVilas, M., Sanjurjo, B., and Navaza, J. M.: Surface tension of organic acids plus water binary mixtures from 20 degrees $\mathrm{C}$ to 50 degrees C, J. Chem. Eng. Data, 42, 957-960, 1997.

Cappa, C. D. and Jimenez, J. L.: Quantitative estimates of the volatility of ambient organic aerosol, Atmos. Chem. Phys., 10, 5409-5424, doi:10.5194/acp-10-5409-2010, 2010.

Cappa, C. D. and Wilson, K. R.: Evolution of organic aerosol mass spectra upon heating: implications for OA phase and partitioning behavior, Atmos. Chem. Phys., 11, 1895-1911, doi:10.5194/acp11-1895-2011, 2011.

Chang, R. Y.-W., Slowik, J. G., Shantz, N. C., Vlasenko, A., Liggio, J., Sjostedt, S. J., Leaitch, W. R., and Abbatt, J. P. D.: The hygroscopicity parameter $(\kappa)$ of ambient organic aerosol at a field site subject to biogenic and anthropogenic influences: relationship to degree of aerosol oxidation, Atmos. Chem. Phys., 10, 50475064, doi:10.5194/acp-10-5047-2010, 2010.

Dal Maso, M., Kulmala, M., Riipinen, I., Wagner, R., Hussein, T., Aalto, P. P., and Lehtinen, K. E. J.: Formation and growth of fresh atmospheric aerosols: eight years of aerosol size distribution data from SMEAR II, Hyytiälä, Finland, Boreal Environ. Res., 10, 323-336, 2005.

Donahue, N. M., Robinson, A. L., Stanier, C. O., and Pandis, S. N.: Coupled partitioning,dilution, and chemical aging of 
semivolatile organics, Environ. Sci. Technol., 40, 2635-2643, 2006.

Donahue, N. M., Robinson, A. L., and Pandis, S. N.: Atmospheric organic particulate matter: From smoke to secondary organic aerosol, Atmos. Environ., 43, 94-106, 2009.

Donahue, N. M., Trump, E. R., Pierce, J. R., and Riipinen, I.: Theoretical constraints on pure vapor-pressure driven condensation of organics to ultrafine particles, Geophys. Res. Lett., 38, L16801, doi:10.1029/2011GL048115, 2011.

Dusek, U., Frank, G. P., Hildebrandt, L., Curtius, J., Schneider, J., Walter, S., Chand, D., Drewnick, F., Hings, S., Jung, D., Borrmann, S., and Andreae, M. O.: Size matters more than chemistry for cloud-nucleating ability of aerosol particles, Science, 312, 1375-1378, 2006.

Egemen, E., Nirmalakhandan, N., and Trevizo, C.: Predicting surface tension of liquid organic solvents, Environ. Sci. Technol., 34, 2596-2600, 2000

Ehn, M., Petäjä, T., Birmili, W., Junninen, H., Aalto, P., and Kulmala, M.: Non-volatile residuals of newly formed atmospheric particles in the boreal forest, Atmos. Chem. Phys., 7, 677-684, doi:10.5194/acp-7-677-2007, 2007.

Eisele, F. L. and Tanner, D. J.: Measurement of the gas phase concentration of $\mathrm{H}_{2} \mathrm{SO}_{4}$ and methane sulfonic acid and estimates of $\mathrm{H}_{2} \mathrm{SO}_{4}$ production and loss in the atmosphere, J. Geophys. Res., 98, 9001-9010, 1993.

Epstein, S. A., Riipinen, I., and Donahue, N. M.: A Semiempirical Correlation between Enthalpy of Vaporization and Saturation Concentration for Organic Aerosol, Environ. Sci. Technol., 44, 743-748, 2010.

Godleski, J. J., Verrier, R. L., Koutrakis, P., Catalano, P., Coull, B., Reinisch, U., Lovett, E. G., Lawrence, J., Murthy, G. G., Wolfson, J. M., Clarke, R. W., Nearing, B. D., and Killingsworth, C.: Mechanisms of morbidity and mortality from exposure to ambient air particles, Res. Rep. Health Eff. Inst., 91, 5-103, 2000.

Hallquist, M., Wenger, J. C., Baltensperger, U., Rudich, Y., Simpson, D., Claeys, M., Dommen, J., Donahue, N. M., George, C., Goldstein, A. H., Hamilton, J. F., Herrmann, H., Hoffmann, T., Iinuma, Y., Jang, M., Jenkin, M. E., Jimenez, J. L., Kiendler-Scharr, A., Maenhaut, W., McFiggans, G., Mentel, Th. F., Monod, A., Prév^t, A. S. H., Seinfeld, J. H., Surratt, J. D., Szmigielski, R., and Wildt, J.: The formation, properties and impact of secondary organic aerosol: current and emerging issues, Atmos. Chem. Phys., 9, 5155-5236, doi:10.5194/acp-95155-2009, 2009.

Hari, P. and Kulmala, M.: Station for measuring ecosystematmosphere relations (SMEAR II), Boreal Eviron. Res., 10, 315$322,2005$.

Jimenez, J. L., Canagaratna, M. R., Donahue, N. M., Prevot, A. S. H., Zhang, Q., Kroll, J. H., DeCarlo, P. F., Allan, J. D., Coe, H., Ng, N. L., Aiken, A. C., Docherty, K. S., Ulbrich, I. M., Grieshop, A. P., Robinson, A. L., Duplissy, J., Smith, J. D., Wilson, K. R., Lanz, V. A., Hueglin, C., Sun, Y. L., Tian, J., Laaksonen, A., Raatikainen, T., Rautiainen, J., Vaattovaara, P., Ehn, M., Kulmala, M., Tomlinson, J. M., Collins, D. R., Cubison, M. J., Dunlea, E. J., Huffman, J. A., Onasch, T. B., Alfarra, M. R., Williams, P. I., Bower, K., Kondo, Y., Schneider, J., Drewnick, F., Borrmann, S., Weimer, S., Demerjian, K., Salcedo, D., Cottrell, L., Griffin, R., Takami, A., Miyoshi, T., Hatakeyama, S., Shimono, A., Sun, J. Y., Zhang, Y. M., Dzepina, K., Kimmel, J.
R., Sueper, D., Jayne, J. T., Herndon, S. C., Trimborn, A. M., Williams, L. R., Wood, E. C., Middlebrook, A. M., Kolb, C. E., Baltensperger, U., and Worsnop, D. R.: Evolution of Organic Aerosols in the Atmosphere, Science, 326, 1525-1529, 2009.

Kanakidou, M., Seinfeld, J. H., Pandis, S. N., Barnes, I., Dentener, F. J., Facchini, M. C., Van Dingenen, R., Ervens, B., Nenes, A., Nielsen, C. J., Swietlicki, E., Putaud, J. P., Balkanski, Y., Fuzzi, S., Horth, J., Moortgat, G. K., Winterhalter, R., Myhre, C. E. L., Tsigaridis, K., Vignati, E., Stephanou, E. G., and Wilson, J.: Organic aerosol and global climate modelling: a review, Atmos. Chem. Phys., 5, 1053-1123, doi:10.5194/acp-5-1053-2005, 2005.

Kerminen, V.-M., Lihavainen, H., Komppula, M., Viisanen, Y., and Kulmala, M.: Direct observational evidence linking atmospheric aerosol formation and cloud droplet activation, Geophys. Res. Lett., 32, L14803, doi:10.1029/2005GL023130, 2005.

Kolb, C. E., Cox, R. A., Abbatt, J. P. D., Ammann, M., Davis, E. J., Donaldson, D. J., Garrett, B. C., George, C., Griffiths, P. T., Hanson, D. R., Kulmala, M., McFiggans, G., Pöschl, U., Riipinen, I., Rossi, M. J., Rudich, Y., Wagner, P. E., Winkler, P. M., Worsnop, D. R., and O' Dowd, C. D.: An overview of current issues in the uptake of atmospheric trace gases by aerosols and clouds, Atmos. Chem. Phys., 10, 10561-10605, doi:10.5194/acp-10-10561-2010, 2010.

Kulmala, M. and Kerminen, V. M.: On the formation and growth of atmospheric nanoparticles, Atmos. Res., 90, 132-150, 2008.

Kulmala, M., Toivonen, A., Mäkelä, J. M., and Laaksonen, A.: Analysis of the growth of nucleation mode particles observed in Boreal forest, Tellus, 50B, 449-462, 1998.

Kulmala, M., Hameri, K., Aalto, P. P., Makela, J. M., Pirjola, L., Nilsson, E. D., Buzorius, G., Rannik, U., Dal Maso, M., Seidl, W., Hoffman, T., Janson, R., Hansson, H. C., Viisanen, Y., Laaksonen, A., and O'Dowd, C. D.: Overview of the international project on biogenic aerosol formation in the boreal forest (BIOFOR), Tellus B, 53, 324-343, 2001.

Kulmala, M., Vehkamäki, H., Petaja, T., Dal Maso, M., Lauri, A., Kerminen, V. M., Birmili, W., and McMurry, P. H.: Formation and growth rates of ultrafine atmospheric particles: a review of observations, J. Aerosol Sci., 35, 143-176, 2004.

Laaksonen, A., Hamed, A., Joutsensaari, J., Hiltunen, L., Cavalli, F., Junkermann, W., Asmi, A., Fuzzi, S., and Facchini, M. C.: Cloud condensation nucleus production from nucleation events at a highly polluted region, Geophys. Res. Lett., 32, L06812, doi:10.1029/2004GL022092, 2005.

Lane, T. E., Donahue, N. M., and Pandis, S. N.: Simulating secondary organic aerosol formation using the volatility basis-set approach in a chemical transport model, Atmos. Environ., 42, 7439-7451, 2008

Lihavainen, H., Kerminen, V. M., Komppula, M., Hatakka, J., Aaltonen, V., Kulmala, M., and Viisanen, Y.: Production of "potential" cloud condensation nuclei associated with atmospheric new particle formation in northern Finland, J. Geophys. Res.-Atmos., 108, 4782, doi:10.1029/2003jd003887, 2003.

Lim, Y. B., Tan, Y., Perri, M. J., Seitzinger, S. P., and Turpin, B. J.: Aqueous chemistry and its role in secondary organic aerosol (SOA) formation, Atmos. Chem. Phys., 10, 1052110539, doi:10.5194/acp-10-10521-2010, 2010.

Makkonen, R., Asmi, A., Korhonen, H., Kokkola, H., Järvenoja, S., Räisänen, P., Lehtinen, K. E. J., Laaksonen, A., Kerminen, V.- 
M., Järvinen, H., Lohmann, U., Bennartz, R., Feichter, J., and Kulmala, M.: Sensitivity of aerosol concentrations and cloud properties to nucleation and secondary organic distribution in ECHAM5-HAM global circulation model, Atmos. Chem. Phys., 9, 1747-1766, doi:10.5194/acp-9-1747-2009, 2009.

Meng, Z. Y. and Seinfeld, J. H.: Time scales to achieve atmospheric gas-aerosol equilibrium for volatile species, Atmos. Environ., 30, 2889-2900, 1996.

Merikanto, J., Spracklen, D. V., Mann, G. W., Pickering, S. J., and Carslaw, K. S.: Impact of nucleation on global CCN, Atmos. Chem. Phys., 9, 8601-8616, doi:10.5194/acp-9-8601-2009, 2009.

Murphy, B. N. and Pandis, S. N.: Simulating the Formation of Semivolatile Primary and Secondary Organic Aerosol in a Regional Chemical Transport Model, Environ. Sci. Technol., 43, 4722-4728, doi:10.1021/es803168a, 2009.

Nieminen, T., Lehtinen, K. E. J., and Kulmala, M.: Sub-10 nm particle growth by vapor condensation - effects of vapor molecule size and particle thermal speed, Atmos. Chem. Phys., 10, 97739779, doi:10.5194/acp-10-9773-2010, 2010.

Odum, J. R., Hoffmann, T., Bowman, F., Collins, D., Flagan, R. C., and Seinfeld, J. H.: Gas/particle partitioning and secondary organic aerosol yields, Environ. Sci. Technol., 30, 2580-2585, 1996.

Pankow, J. F.: An absorption model of gas/particle partitioning of organic compounds in the atmosphere, Atmos. Environ., 28, 185-188, 1994.

Pathak, R. K., Presto, A. A., Lane, T. E., Stanier, C. O., Donahue, N. M., and Pandis, S. N.: Ozonolysis of a-pinene: parameterization of secondary organic aerosol mass fraction, Atmos. Chem. Phys., 7, 3811-3821, doi:10.5194/acp-7-3811-2007, 2007.

Petäjä, T., Mauldin, III, R. L., Kosciuch, E., McGrath, J., Nieminen, T., Paasonen, P., Boy, M., Adamov, A., Kotiaho, T., and Kulmala, M.: Sulfuric acid and $\mathrm{OH}$ concentrations in a boreal forest site, Atmos. Chem. Phys., 9, 7435-7448, doi:10.5194/acp9-7435-2009, 2009.

Peters, A., Wichmann, H. E., Tuch T., Heinrich J., and Heyder J.: Respiratory effects are associated with the number of ultrafine particles, Am. J. Respir. Crit. Care Med., 155, 1376-1383, 1997.

Pierce, J. R. and Adams, P. J.: Efficiency of cloud condensation nuclei formation from ultrafine particles, Atmos. Chem. Phys., 7, 1367-1379, doi:10.5194/acp-7-1367-2007, 2007.

Pierce, J. R. and Adams, P. J.: Uncertainty in global CCN concentrations from uncertain aerosol nucleation and primary emission rates, Atmos. Chem. Phys., 9, 1339-1356, doi:10.5194/acp-91339-2009, 2009a.

Pierce, J. R. and Adams, P. J.: A Computationally Efficient Aerosol Nucleation/Condensation Method: Pseudo-Steady-State Sulfuric Acid, Aerosol Sci. Technol., 43, 1-11, 2009b.

Raatikainen, T., Vaattovaara, P., Tiitta, P., Miettinen, P., Rautiainen, J., Ehn, M., Kulmala, M., Laaksonen, A., and Worsnop, D. R.: Physicochemical properties and origin of organic groups detected in boreal forest using an aerosol mass spectrometer, Atmos. Chem. Phys., 10, 2063-2077, doi:10.5194/acp-10-20632010, 2010.
Riipinen, I., Pierce, J. R., Donahue, N. M., Pandis, S. N.: Equilibration time scales of organic aerosol inside thermodenuders: Evaporation kinetics versus thermodynamics, Atmos. Environ., 44, 597-607, 2010.

Riipinen, I., Pierce, J. R., Yli-Juuti, T., Nieminen, T., Häkkinen, S., Ehn, M., Junninen, H., Lehtipalo, K., Petäjä, T., Slowik, J., Chang, R., Shantz, N. C., Abbatt, J., Leaitch, W. R., Kerminen, V.-M., Worsnop, D. R., Pandis, S. N., Donahue, N. M., and Kulmala, M.: Organic condensation: a vital link connecting aerosol formation to cloud condensation nuclei (CCN) concentrations, Atmos. Chem. Phys., 11, 3865-3878, doi:10.5194/acp-11-38652011, 2011.

Seinfeld, J. H. and Pandis, S. N.: Atmospheric Chemistry and Physics, 2nd ed., John Wiley and Sons, New York, 2006.

Smith, J. N., Barsanti, K. C., Friedli, H. R., Ehn, M., Kulmala, M., Collins, D. R., Scheckman, J. H., and McMurry, P. H.: Observations of aminium salts in atmospheric nanoparticles and possible climatic implications, P. Natl. Acad. Sci., 107, 6634-6639, 2010.

Spracklen, D. V., Carslaw, K. S., Merikanto, J., Mann, G. W., Reddington, C. L., Pickering, S., Ogren, J. A., Andrews, E., Baltensperger, U., Weingartner, E., Boy, M., Kulmala, M., Laakso, L., Lihavainen, H., Kivekäs, N., Komppula, M., Mihalopoulos, N., Kouvarakis, G., Jennings, S. G., O’Dowd, C., Birmili, W., Wiedensohler, A., Weller, R., Gras, J., Laj, P., Sellegri, K., Bonn, B., Krejci, R., Laaksonen, A., Hamed, A., Minikin, A., Harrison, R. M., Talbot, R., and Sun, J.: Explaining global surface aerosol number concentrations in terms of primary emissions and particle formation, Atmos. Chem. Phys., 10, 4775-4793, doi:10.5194/acp-10-4775-2010, 2010.

Twomey, S.: Pollution and the Planetary Albedo, Atmos. Environ., 8, 1251-1256, 1974.

Twomey, S.: The Influence of Pollution on the Shortwave Albedo of Clouds, J. Atmos. Sci., 34, 1149-1152, 1977.

Twomey, S.: Aerosols, Clouds, and Radiation, Atmos. Environ., 25A, 2435-2442, 1991.

Virtanen, A., Joutsensaari, J., Koop, T., Kannosto, J., Yli-Pirilä, P., Leskinen, J., Mäkelä, J. M., Holopainen, J. K., Pöschl, U., Kulmala, M., Worsnop, D. R., and Laaksonen, A.: An amorphous solid state of biogenic secondary organic aerosol particles, Nature, 467, 824-827, 2010.

Wang, L., Khalizov, A. F., Zheng, J.. Xu, W., Ma, Y., Lal, V., and Zhang, R.: Atmospheric nanoparticles formed from heterogeneous reactions of organics, Nature Geosci., 3, 238-242, 2010.

Wang, M. and Penner, J. E.: Aerosol indirect forcing in a global model with particle nucleation, Atmos. Chem. Phys., 9, 239-260, doi:10.5194/acp-9-239-2009, 2009.

Yu, F.: A secondary organic aerosol formation model considering successive oxidation aging and kinetic condensation of organic compounds: global scale implications, Atmos. Chem. Phys., 11, 1083-1099, doi:10.5194/acp-11-1083-2011, 2011.

Yu, F. and Luo, G.: Simulation of particle size distribution with a global aerosol model: contribution of nucleation to aerosol and CCN number concentrations, Atmos. Chem. Phys., 9, 76917710, doi:10.5194/acp-9-7691-2009, 2009. 